Invited review

\title{
Peptides and peptide-derived molecules targeting the intracellular domains of Cx43: Gap junctions versus hemichannels ${ }^{\text {th }}$
}

\author{
Q3 Jegan Iyyathurai ${ }^{\mathrm{a}, 1}$, Catheleyne D’hondt ${ }^{\mathrm{a}, 1}$, Nan Wang ${ }^{\mathrm{b}}$, Marijke De Bock ${ }^{\mathrm{b}}$, Bernard Himpens ${ }^{\mathrm{a}}$, \\ Mauricio A. Retamal ${ }^{c}$, Jimmy Stehberg ${ }^{d, e}$, Luc Leybaert ${ }^{b}$, Geert Bultynck ${ }^{a, *}$ \\ ${ }^{a}$ Laboratory of Molecular and Cellular Signaling, Department of Cellular and Molecular Medicine, Campus Gasthuisberg O/N-I Bus 802, KU Leuven, Herestraat 49, \\ BE-3000 Leuven, Belgium \\ ${ }^{\mathrm{b}}$ Faculty of Medicine and Health Sciences, Physiology Group, Department of Basic Medical Sciences, Ghent University, De Pintelaan 185 (Block B-Rm 310 ), B-9000 Ghent, Belgium \\ ${ }^{\mathrm{c}}$ Departamento de Fisiología, Facultad de Medicina, Clínica Alemana-Universidad del Desarrollo, Santiago, Chile \\ ${ }^{\mathrm{d}}$ Laboratorio de Neurobiologia, Departamento de Ciencias Biologicas, Facultad de Ciencias Biologicas E Facultad de Medicina, Universidad Andres Bello, Santiago, Chile \\ e Centro de Investigaciones Biomédicas, Universidad Andres Bello, Santiago, Chile
}

\section{A R T I C L E I N F O}

\section{Article history:}

Received 2 January 2013

Received in revised form

17 April 2013

Accepted 18 April 2013

\section{Keywords:}

Connexin

Gap junctions

Hemichannels

Intramolecular interactions

Cytoplasmic loop

C-terminal tail

Peptides

Ischemia

Brain

Heart

\begin{abstract}
A B S T R A C T
About a decade ago, the molecular determinants controlling the opening and closing of Cx43 gap junction channels have been identified. Advanced biophysical approaches revealed a critical role for structural rearrangements in the cytoplasmic loop and dimerization of the C-terminal tail, resulting in binding of the C-terminal tail to the cytoplasmic loop and $\mathrm{Cx} 43$ gap junction channel closure during cellular acidosis. This has spurred the development of $\mathrm{Cx} 43$-mimetic peptides and peptidomimetics that interfere with these loop/tail interactions, thereby preventing the closure of $\mathrm{Cx} 43$ gap junctions, e.g. in the heart upon ischemia. Recently, we found that loop/tail interactions control Cx43-hemichannel activity but with an opposite effect. Binding of the C-terminal tail to the cytoplasmic loop is a requisite for the opening of $\mathrm{Cx} 43$ hemichannels in response to different stimuli, like decreased extracellular $\left[\mathrm{Ca}^{2+}\right]$, increased intracellular $\left[\mathrm{Ca}^{2+}\right]$, positive membrane potentials or ischemia. Strikingly, peptides that favor the open state of $\mathrm{Cx} 43$ gap junctions like the L2 peptide inhibit $\mathrm{Cx} 43$-hemichannel opening. These tools now provide unprecedented opportunities to selectively inhibit $\mathrm{Cx} 43$ hemichannels while maintaining Cx43 gap junction communication, impossible to achieve with siRNA or knockdown approaches both affecting gap junctions and hemichannels. These tools not only are very helpful to unravel the role of Cx43 hemichannels in complex biological systems, but also hold therapeutic potential to counteract excessive $\mathrm{Cx} 43$-hemichannel activity like in ischemia/reperfusion in the brain and the heart or to prevent Cx43 hemichannel-mediated gliotransmitter release in the basal amygdala during memory consolidation in response to emotional events.
\end{abstract}

This article is part of a Special Issue entitled 'Connexin based channels'.

(C) 2013 The Authors. Published by Elsevier Ltd. All rights reserved.

\section{Introduction}

Intercellular communication is critical for regulating a plethora of physiological processes in many organs and tissues critical for life, including the brain, heart, kidney, liver, pancreas, lung, arteries, ovary, bone, inner ear, skin, lens, retina and cornea as most

\footnotetext{
is This is an open-access article distributed under the terms of the Creative Commons Attribution-NonCommercial-No Derivative Works License, which permits non-commercial use, distribution, and reproduction in any medium, provided the original author and source are credited.

* Corresponding author. Tel.: +32 16330215.

E-mail address: geert.bultynck@med.kuleuven.be (G. Bultynck).

1 The authors equally contributed to this work.
}

important ones (Kar et al., 2012; Leybaert and Sanderson, 2012; Saez et al., 2003). For instance, the synchronization of the contraction of cardiomyocytes, the coordination of metabolic networks in the brain and the generation of rhythmic contractions in the arteries critically depend on the proteins that establish intercellular communication, the connexins $(\mathrm{Cx})$ and pannexins (Panx)-protein family (Billaud et al., 2012; Delmar and Makita, 2012). These proteins are ubiquitously expressed in human tissues and are encoded by 21 genes for Cxs and 3 genes for Panxs (D'hondt et al., 2009; Scemes et al., 2009, 2007). These proteins assemble in hexameric channel complexes (though Panx2 might form an octamer (Ambrosi et al., 2010)), which can either function as head-to-head-docked gap junction channels establishing direct cell-to-cell contacts or free unapposed hemichannels establishing http://dx.doi.org/10.1016/j.neuropharm.2013.04.050 
release nodes for signaling molecules affecting neighboring cells (D'hondt et al., 2009; Herve and Derangeon, 2012; Scemes et al., 2009). It is well established that $C x$ isoforms can function both as gap junction channels and hemichannels (Evans et al., 2006; Kar et al., 2012). For Panx isoforms, recent evidence from overexpression studies suggests that they may also function as gap junction channels (Ishikawa et al., 2011) although still under debate (Sosinsky et al., 2011). Moreover, Cx and Panx channels may also appear at intracellular membranes, including the mitochondria and the endoplasmic reticulum (ER), where they may function as nonjunctional channels. $\mathrm{C} \times 43$ found at the inner mitochondrial membrane has been implicated in $\mathrm{K}^{+}$flux into the mitochondria of cardiomyocytes (Miro-Casas et al., 2009), whereas ER-localized Panx channels may function as intracellular $\mathrm{Ca}^{2+}$ leak/release channels (D'hondt et al., 2011; Ishikawa et al., 2011; Vanden Abeele et al., 2006). Very recently, a new protein family, $\mathrm{Ca}^{2+}$-homeostasis modulator 1 (CALHM1), has been identified and reported to resemble structurally and functionally $\mathrm{Cx} / \mathrm{Panx}$ channels (Siebert et al., 2013). CALHM1 seems to function as a nonjunctional channel responsible for ATP release, especially in the taste bud cells, involved in the sensation of bitter, sweet and umami tastes (Taruno et al., 2013).

In this review, we will focus on the $43-\mathrm{kDa} C \mathrm{Cx}$ isoform $(\mathrm{Cx} 43)$, which is highly and widely expressed, in particular in the heart and the brain (Kar et al., 2012; Scemes et al., 2009). The biological role of Cxs, including Cx43, as gap junction and nonjunctional channels has recently and extensively been discussed in other reviews (Chandrasekhar and Bera, 2012; Kar et al., 2012; Wang et al., 2013a). In short, as reported in many cell types and tissues, Cx-based gap junctions provide ionic/electrical conductance $\left(\mathrm{Na}^{+}, \mathrm{K}^{+}, \mathrm{Ca}^{2+}\right)$, metabolic coupling (ATP/ADP, glucose, glutamate, glutathione) and spreading of secondary messenger molecules ( $\left.\mathrm{IP}_{3}, \mathrm{CAMP}\right)$ between cells (Kar et al., 2012). Also, Cx-based hemichannels mediate the flux of many substances, including ions and molecules with a molecular weight (MW) lower than $1-2 \mathrm{kDa}$, including ATP, NAD ${ }^{+}$, glutamate, glutathione, prostaglandin $\mathrm{E}_{2}$ and epoxyeicosatrienoic acids (D'hondt et al., 2009; Wang et al., 2013a). These molecules provide local/paracrine signaling networks implicated in the control and coordination of intracellular and intercellular signaling pathways involved in cell survival, proliferation and death (Decrock et al., 2013, 2009b; Leybaert and Sanderson, 2012). The physiological role of $\mathrm{Cx}$ hemichannels has been questioned (Scemes, 2012), although it is increasingly clear that diverse stimuli within physiological conditions can modulate the opening of $\mathrm{Cx}$ hemichannels, including low extracellular $\left[\mathrm{Ca}^{2+}\right]$ as occurs during neuronal synaptic signaling (Torres et al., 2012), moderate elevation of intracellular $\left[\mathrm{Ca}^{2+}\right]$ in the physiological range of $\sim 500 \mathrm{nM}$ (De Vuyst et al., 2006; De Vuyst et al., 2009; Wang et al., 2012, 2013a) and mechanical forces/shear stress (Loiselle et al., 2012). Furthermore, physiological elevations of intracellular $\left[\mathrm{Ca}^{2+}\right]$ shifted the threshold for voltage-dependent opening of $\mathrm{Cx} 43$ hemichannels from $+60 \mathrm{mV}$ to $+40 \mathrm{mV}$ and lower (Wang et al., 2012). This indicates that physiological $\mathrm{Ca}^{2+}$ signaling may sensitize the opening of $\mathrm{Cx} 43$ hemichannels in response to membrane polarization to potentials in the $+30-40 \mathrm{mV}$ range which may occur in electrically excitable cells. On the other hand, the excessive opening of $\mathrm{Cx}$ hemichannels can be limited physiologically by the actomyosin cytoskeleton involving $\mathrm{Ca}^{2+}$ and RhoA signaling, thus avoiding detrimental effects on cellular homeostasis (Ponsaerts et al., 2008, 2012a,b). Finally, post-translation modifications can also influence and regulate the activity of $\mathrm{Cx} 43$ hemichannels (Johnstone et al., 2012).

The monomeric Cx43-building blocks that form hexameric channels consist of a 382 amino acid-long protein (based on the human CX43 sequence; NCBI Reference Sequence: NP_000156.1) containing four-transmembrane domains with two extracellular loops, one cytoplasmic loop domain and an $\mathrm{N}$ - and C-terminus that faces the cytoplasmic side. The $\mathrm{N}$-terminus is relatively short (13 amino acids), while the C-terminus is relatively long ( $\sim 150$ amino acids). The C-terminus is very important for the regulation of Cx43-gap junction channels, containing a number of phosphorylation sites, protein-interaction sites and motifs as well as redox-sensitive residues (three Cys residues) (Herve et al., 2007; Johnstone et al., 2012; Palatinus et al., 2012; Solan and Lampe, 2009). In this review, we will focus on the role of loop/tail interactions for controlling the activity of $\mathrm{Cx} 43$ gap junction channels and hemichannels. We will also discuss how recent insights on the key determinants underlying loop/tail interactions and their functional outcome for $\mathrm{Cx} 43$ gap junction channels and hemichannels has spurred the development of novel peptides and peptidomimetics with therapeutic potential. In particular, recent advances resulted in the identification of peptides that can sustain gap junction coupling in disease conditions and peptides that can prevent excessive hemichannel opening under certain pathological conditions (Evans et al., 2012). These peptides are promising tools to explore the role of gap junctions and $\mathrm{Cx}$ hemichannels in pathological conditions and diseases, and offer interesting possibilities towards defining novel molecular therapeutic targets (De Vuyst et al., 2011; Evans et al., 2012; Herve and Dhein, 2010).

\section{Intramolecular loop/tail interactions in $\mathrm{Cx} 43$ gap junction channels and their functional consequences}

\subsection{Gap junction channels paved the path}

About twenty years ago, the role of intramolecular interactions in the gating of $\mathrm{Cx} 43$ gap junction channels started to emerge (Liu et al., 1993). The original findings were directed towards providing a mechanistic basis for the intracellular acidification-mediated closure of Cx43 gap junction channels (Spray et al., 1981), but were also found to be applicable to other forms of chemical gating, for example gap junction closure induced by insulin (Homma et al., 1998). Liu et al. found that Cx43-based gap junction channels were particularly sensitive to a decrease in intracellular $\mathrm{pH}\left(\mathrm{pH}_{\mathrm{i}}\right)$ compared to $\mathrm{Cx} 32$ or $\mathrm{CT}$-truncated $\mathrm{Cx} 43\left(\mathrm{Cx} 43^{\mathrm{M} 257}\right)$-based gap junction channels (Liu et al., 1993). The junction conductance rapidly decreased starting from $\mathrm{pH}_{\mathrm{i}} 6.8$ and lower for $\mathrm{Cx} 43$, while for $\mathrm{Cx} 32$ and $\mathrm{Cx} 43^{\mathrm{M} 257}$, junction conductance only started to decrease from pH 6.3 and below (Fig. 2). Hence, the C-terminal tail Q1 of $\mathrm{Cx} 43$ seemed critical for the pH-dependent gating of the $\mathrm{Cx} 43$ gap junction channels. Further work revealed critical elements in the cytoplasmic loop and its preceding transmembrane domain (transmembrane domain 2, see Fig. 3), revealing a critical role for His95 (Ek et al., 1994). Replacing His95 to Asp or Tyr led to functional $\mathrm{Cx} 43$ gap junctions that displayed a decreased susceptibility towards intracellular acidification. In contrast, replacing His95 to Lys led to functional Cx43 gap junctions that displayed an increased susceptibility towards intracellular acidification. Thus, His95 is critical for the $\mathrm{pH}$-dependent regulation of $\mathrm{Cx} 43$ gating, likely via a protonation mechanism that would lead to a positively charged residue, strengthening the interaction with the negatively charged CT. Follow-up studies showed that the lack of sensitivity of $\mathrm{Cx} 43^{\mathrm{M} 257}$ gap junction channels to intracellular acidification (in the range between $\mathrm{pH} 7.2$ to $\mathrm{pH}$ 6.4) was restored upon co-expression of the C-terminal tail (amino acids 259-382) (Morley et al., 1996). Hence, the C-terminal tail of $\mathrm{CX} 43$ acts as a separate and independent domain that binds to a region preceding the $\mathrm{C}$-terminal tail and closes $\mathrm{Cx} 43$-gap junction channels upon intracellular acidification. Elements in the first 257 amino acids were proposed to act 


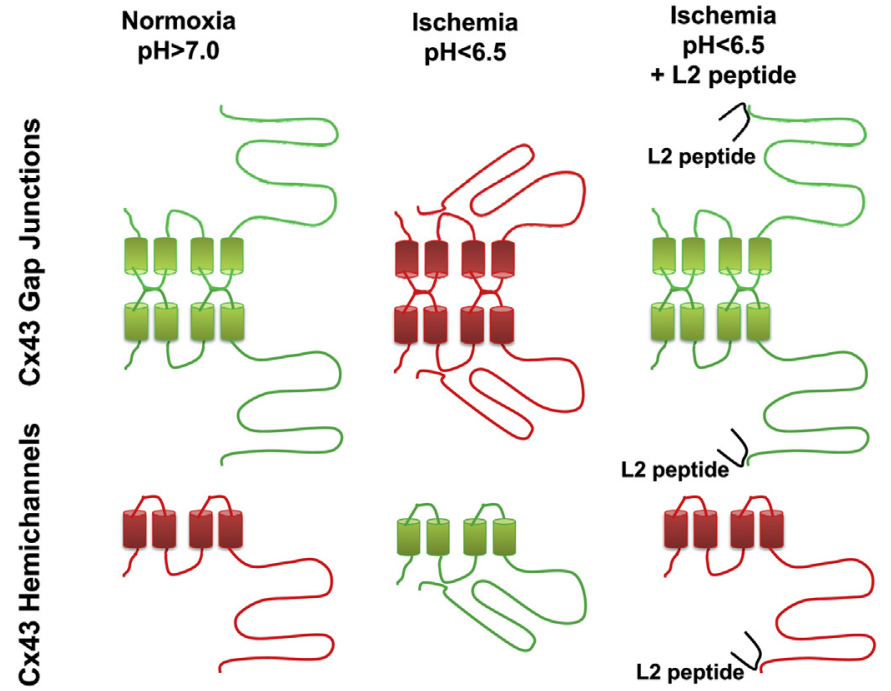

Fig. 1. Schematic representation of $\mathrm{Cx} 43$ gap junctions and hemichannels in the open and closed state. The $\mathrm{Cx} 43$ protein is the building block for gap junctions and hemichannels, consisting of a short N-terminus, 4 transmembrane domains, two extracellular loops, one cytoplasmic loop and a long C-terminal tail. Functional channels consist of hexameric structures that are head-to-head docked to form gap junctions or that are unopposed to form hemichannels. Gap junctions: At normal conditions $(\mathrm{pH}>7.0)$, gap junctions are open (green) and the C-terminal tail does not interact with the cytoplasmic loop. During ischemia (or other conditions that cause a drop in $\mathrm{pH}$ ), the C-terminal tail dimerizes and the cytoplasmic loop restructures adopting two alpha-helical structures at the proximal and distal part of the L2 region, resulting in the binding of the C-terminal tail to the cytoplasmic loop and the closure of gap junction channels (red). Peptides like L2 (but also others) interfere with these loop/tail interactions by replacing the endogenous cytoplasmic loop of $\mathrm{Cx} 43$ and serving as a binding partner for the C-terminal rail, maintaining the open state of gap junction channels (green). Hemichannels: At normal condtions ( $\mathrm{pH} \sim 7.0)$, hemichannels are closed (red) due to the lack of the binding of C-terminal tail to the cytoplasmic loop. During ischemia, but also other conditions that open hemichannels like a decrease in extracellular $\left[\mathrm{Ca}^{2+}\right]$ or increase in intracellular $\left[\mathrm{Ca}^{2+}\right]$ (up to $500 \mathrm{nM}$ ), hemichannels are opened (green) due to the binding of the C-terminal tail to the cytoplasmic. Peptides like L2 and Gap19 interfere with the loop/tail interactions by binding to the Cterminal tail and preventing endogenous loop/tail interactions that are critical for hemichannel opening. For clarity reasons, the monomeric building blocks are depicted, but it should be noted that the functional hemichannel unit is hexameric.

\section{Normoxia} $\mathrm{pH}>7.0$
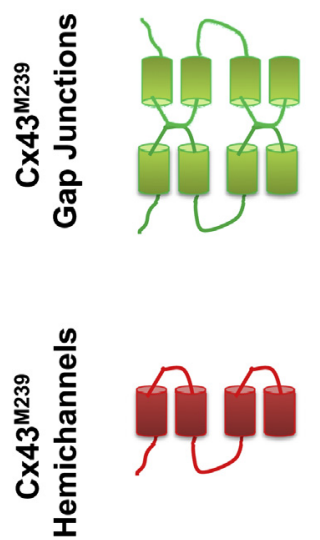

\section{Ischemia}

$\mathrm{pH}<6.5$
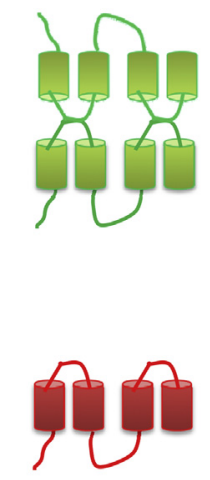

Fig. 2. Function of C-terminally truncated Cx43 gap junctions and hemichannels. Gap junctions: C-terminally truncated Cx43 gap junctions remain open, but are resistant to low $\mathrm{pH}_{\mathrm{i}}$-induced closure. Hemichannels: C-terminally truncated $\mathrm{Cx} 43$ hemichannels remain closed, even at low $\mathrm{pH}_{\mathrm{i}}$ or other stimuli, like decreased extracellular $\left[\mathrm{Ca}^{2+}\right]$ or increased intracellular $\left[\mathrm{Ca}^{2+}\right]$. As in Fig. 1, only monomeric building blocks are shown for clarity. as a receptor for elements in the last 124 amino acids, acting as a particle (Morley et al., 1996). Two regions within the C-terminal tail of Cx43 were found to be particularly critical for intracellular acidification-induced uncoupling, one region covers amino acids 261-300 and another region covers amino acids 374-382 (EkVitorin et al., 1996). Deleting these two regions in Cx43 renders these gap junction channels relatively insensitive to intracellular acidification-induced uncoupling. Region 261-300 contains a proline-rich region, identified as the SH3-binding domain of Src, a protein tyrosine kinase (Kanemitsu et al., 1997; Sorgen et al., 2004a). Pro277 and Pro280 seem to play a critical role in the structural integrity of this region. Mutating these Pro residues into Ala results in $\mathrm{Cx} 43$ gap junction channels resistant to intracellular acidification, which mimics the behavior of $\mathrm{Cx} 43^{\Delta 261-300}$ gap junction channels. Region 374-382, which corresponds to the PDZ2-binding site for Zonula Occludens-1 (ZO-1) (Giepmans and Moolenaar, 1998; Sorgen et al., 2004a), also contains two Pro residues (Pro375 and Pro377) and a set of positively (Arg374 and Arg376) and negatively charged residues (Asp378, Asp379 and Glu381). The three negative charges seemed critical for the $\mathrm{pH}_{\mathrm{i}}$ gating of the $\mathrm{Cx} 43$ gap junction channels, as the simultaneous mutation of these residues abolished the $\mathrm{pH}_{\mathrm{i}}$-induced closure of these channels. Thus, interactions of the particle with its receptor domain seem to depend on ionic and non-ionic interactions. These concepts may not necessarily be limited to domain interactions within $\mathrm{Cx}_{\mathrm{X}}$ 3, but may also be applicable for some other Cx isoforms, like Cx40 (Gu et al., 2000; Stergiopoulos et al., 1999). Certainly, not all $\mathrm{Cx}$ isoforms display this regulation. For example, C-terminal truncation of $\mathrm{Cx} 45$ did not affect its $\mathrm{pH}_{\mathrm{i}}$-dependent regulation (Stergiopoulos et al., 1999). Furthermore, also hetero-domain interactions may occur, as shown between $\mathrm{Cx} 43$ and $\mathrm{Cx} 40$. The $\mathrm{pH}_{\mathrm{i}^{-}}$ dependent regulation of C-terminally truncated $\mathrm{Cx} 43$ could be restored by the $\mathrm{C}$-terminal tail of $\mathrm{Cx} 40$ and vice versa, while the $\mathrm{C}$ terminal tail of $\mathrm{C} x 43$ could render $\mathrm{Cx} 26$ and $\mathrm{Cx} 32$, which normally are resistant to chemically-induced closure, sensitive to insulin (Stergiopoulos et al., 1999). All these functional studies hinted towards a critical role for the C-terminal tail of $\mathrm{Cx} 43$ in $\mathrm{pH}_{\mathrm{i}}$-dependent regulation of $\mathrm{Cx} 43$ gap junction channels through intramolecular interactions. A detailed molecular analysis using different biophysical approaches led to the identification of the second part of the cytoplasmic loop (the $\mathrm{L} 2$ region corresponding to amino acids 119-144 of $\mathrm{Cx} 43$ ) as the receptor for the C-terminal tail particle (Duffy et al., 2002) (Fig. 3). The authors showed a pHdependent interaction between the $\mathrm{L} 2$ region and the C-terminal tail of $\mathrm{Cx} 43$. A strong interaction between $\mathrm{L} 2$ and the $\mathrm{C}$-terminal tail of $\mathrm{Cx} 43$ was observed at $\mathrm{pH} 6.5$, while binding was not observed at $\mathrm{pH}$ 7.4. Importantly, the $\mathrm{L} 2$ region contains two His residues (His126 and His144), which are protonated at low pH and are likely involved in structural rearrangements of the L2 region (Fig. 2). These two His residues are located in two separate regions that were shown to form alpha helices in the solution structure of the L2 region obtained at $\mathrm{pH}$ 5.8. The critical role of these His residues in the gating of $\mathrm{Cx} 43$ gap junction channels was further underpinned by the analysis of $\mathrm{C} x 43^{\mathrm{H} 144 \mathrm{E}}$ gap junction channels (Shibayama et al., 2006). These channels displayed a reduced occurrence in the residual state and a prolonged dwelling in the open state; very similar to C-terminally truncated $\mathrm{Cx} 43$ channels. These functional observations are underpinned by evidence from NMR studies showing that an L2 peptide in which His144 was changed into Glu displayed i) a decrease in the interaction with the C-terminal tail of Cx43 and ii) a disrupted secondary structure (Shibayama et al., 2006). In contrast to $\mathrm{L} 2$, the solution structure of $\mathrm{L} 2^{\mathrm{H} 144 \mathrm{E}}$ failed to form two alpha-helical regions at $\mathrm{pH}$ 5.8. Besides the role of the L2 region in channel closure upon acidosis, this region also seems important for proper channel-pore organization. Indeed, gap 

loss of electrical communications, despite their ability to form plaques (Seki et al., 2004a). Furthermore, the interaction between the loop and the C-terminal tail at low pH may also depend on homo-oligomerization, which is induced upon intracellular acidification (Hirst-Jensen et al., 2007). Different regions in the C-terminal tail are involved in the homodimerization of the C-terminal tail, including regions covered by amino acids $281-295,299-304$, 314-327, 340-348 and 364-382. These regions display considerable overlap with regions involved in the interaction with the cytoplasmic loop. Regions covered by amino acids 343-346 and 377-379 strongly contributed to cytoplasmic loop binding, while regions covered by amino acids $312-332$, 335-340, 347-349, 357$361,364-374$ and 380-382 weakly contribute to cytoplasmic loop binding. Importantly, deletion of regions that affect homodimerizations also affects the binding of the cytoplasmic loop domain. Based on these findings, it was proposed that dimerization of the C-terminal tail upon low $\mathrm{pH}$ is critical for interaction with the cytoplasmic loop domain (Hirst-Jensen et al., 2007). Beyond its role in chemical gating of $\mathrm{Cx} 43$, the C-terminal tail regulates the localization, number and size of $\mathrm{Cx} 43$ plaques in vivo, probably through interaction with accessory proteins (Maass et al., 2007). These accessory proteins and post-translational modifications may also control the closure of $\mathrm{Cx} 43$ gap junction channels. For instance, binding of Src via its $\mathrm{SH} 3$ domain and $\mathrm{SH} 2$ domain to the prolinerich region and the phosphorylated Tyr265 residue of $\mathrm{Cx} 43$, respectively, leads to Src-mediated phosphorylation of $\mathrm{Cx} 43$ on Tyr247 (Kanemitsu et al., 1997). Mutations in the SH3-binding domain of Cx43 of Tyr265 result in defective Src binding and phosphorylation. Expression of Src and phosphorylation of Tyr247/ 265 disrupts $\mathrm{Cx} 43$-mediated gap junction communication between cells, but not in cells expressing $\mathrm{Cx} 43^{\mathrm{Y} 265 \mathrm{~F}}$ or $\mathrm{Cx} 43 \Delta 265$ (Giepmans et al., 2001). Physiological Src signaling occurs downstream of Gprotein-coupled receptor signaling, leading to the loss of cell-cell communication (Postma et al., 1998). Interestingly, the binding of Src to $\mathrm{Cx} 43$ is highly $\mathrm{pH}$-dependent, being enhanced at low $\mathrm{pH}$ (Duffy et al., 2004). Another important binding partner of the Cterminal tail of $\mathrm{Cx} 43$ is the scaffolding protein ZO-1 (Giepmans and Moolenaar, 1998; Toyofuku et al., 1998), which stabilizes Cx43 gap junction channel formation (Giepmans and Moolenaar, 1998), determines the size of gap junctions (Hunter et al., 2005) and localization of gap junctions (Palatinus et al., 2011a), and regulates the rate of connexon docking (Rhett et al., 2011). Increased binding of constitutively active Src to $\mathrm{Cx} 43$ coincided with decreased Cx43/ ZO-1-complex formation (Toyofuku et al., 2001). This interdependence is underpinned by the fact that the increased binding of Src to $\mathrm{Cx} 43$ at low pH also prevents and reversed the binding of ZO- 1 to Cx43, resulting in ZO-1-stripped Cx43-gap junction channels (Duffy et al., 2004). As a consequence of this, the internalization of Cx43 gap junctions is enhanced. To summarize, intracellular acidification, as occurs during ischemia, leads to the closure of $\mathrm{Cx} 43-$ based gap junction channels through an increased dimerization of the C-terminal tail and concomitant structural arrangement in the cytoplasmic domain of $\mathrm{Cx} 43$, resulting in a binding of the Cterminal tail to the cytoplasmic domain. In addition, low intracellular $\mathrm{pH}$ will result in the stripping of $\mathrm{ZO}-1$ from $\mathrm{Cx} 43$ gap junction channels through the recruitment of Src, which facilitates the closure of $\mathrm{Cx} 43$ gap junction channels and ultimately results in an increased internalization of $\mathrm{Cx} 43$ gap junction channels and a reduced fraction of plasmalemmal $\mathrm{Cx} 43$ gap junctions. In any case, the C-terminal tail, its binding partners and post-translational modifications are dispensable for the targeting and the formation of functional $\mathrm{Cx} 43$ gap junction channels (Hunter and Gourdie, 2008; Maass et al., 2007). 
2.2. Loop and C-terminal tail Cx43-mimetic peptides and their effects on Cx43 gap junction channels

In this section, we provide a systematic overview of the different peptides and peptide-derived molecules that are based on intracellular Cx43 sequences proposed to be involved in loop/tail interactions. These peptides and peptide-derived molecules therefore are believed to target the critical regions in the cytoplasmic loop or C-terminal tail, thereby preventing the occurrence of "endogenous" $\mathrm{Cx} 43$ loop/tail interactions that result in the closure of $\mathrm{Cx} 43$ gap junction channels.

\subsubsection{The SH3-binding domain peptide}

A 17-mer peptide corresponding to amino acids 271-287 (CSSPTAPLSPMSPPGYK), which is the proline-rich region forming the SH3-binding domain for Src, was used as a molecule to interfere with the $\mathrm{pH}_{\mathrm{i}}$-dependent gating of $\mathrm{Cx} 43$ gap junction channels (Calero et al., 1998) (Fig. 3). Injection of this peptide in Cx43expressing and pair-forming oocytes completely abolished the intracellular acidification-mediated closure of $\mathrm{Cx} 43$ gap junction channels, while normal $\mathrm{pH}_{\mathrm{i}}$-dependent gating was observed in cells injected with a scrambled version (Calero et al., 1998). The mechanism could involve different possibilities. The 17-mer peptide could act as the direct target for the receptor located in the cytoplasmic loop, thereby preventing the binding of the C-terminal tail to the loop. In addition, this 17-mer peptide also partially overlaps with regions responsible for C-terminal tail dimerization, an important step in the binding of the cytoplasmic loop and inhibition of Cx43 gap junction channels (Hirst-Jensen et al., 2007). Finally, this 17-mer peptide can also interfere with the recruitment of Src to Cx43 and the subsequent Tyr265 phosphorylation of Cx43 (known to inhibit $\mathrm{Cx} 43$ gap junction channels), thereby preventing Src-mediated $\mathrm{Cx} 43$ gap junction inhibition at low pH (Kanemitsu et al., 1997).

\subsubsection{The C-terminal CT9 peptide}

A 9-mer peptide corresponding to the last 9 amino acids of the C-terminal tail of $\mathrm{Cx} 43$ (CT9) has been developed (Fig. 3). This sequence has different biological properties, including binding to the cytoplasmic loop domain (Hirst-Jensen et al., 2007; Ponsaerts et al., 2010), binding to the PDZ-2 domain of ZO-1 (Hunter et al., 2005; Sorgen et al., 2004a) and increasing PKC-epsilon-mediated phosphorylation of $\mathrm{Cx} 43$ after left ventricular injury in a cryoinjury model (O'Quinn et al., 2011; Palatinus et al., 2011b). A cellpermeable version of the CT9 peptide, called ACT1, was developed by Gourdie and co-workers, serving as an inhibitor of ZO-1 interaction by targeting its PDZ2 domain (Hunter et al., 2005). ACT1 caused an increase in $\mathrm{Cx} 43$ gap junction size by facilitating the transfer from nonjunction $\mathrm{Cx} 43$ pools into gap junction plaques, a process that seems to be limited and tightly controlled by ZO- 1 (Hunter et al., 2005). ACT1 decreased the interaction of Cx43 with ZO- 1 at the perinexus, thereby increasing the presence of $\mathrm{Cx} 43$ as gap junctions and decreasing its presence as hemichannels (Palatinus et al., 2012; Rhett and Gourdie, 2012). As a consequence of this shift in gap junction/hemichannel ratio, ACT1 increased Cx43 gap junction communication and decreased Cx43hemichannel function. These effects were related to altered ZO-1 function, since ZO-1 knockdown recapitulated these effects of ACT1. Also, ACT1 seems to provide a relatively rapid shift in Cx43 gap junction partitioning, which occurred within $2 \mathrm{~h}$ of ACT1 exposure to cells (Rhett et al., 2011). In any case, while these ACT1 effects on gap junctions seem to represent a remodeling of the amount of Cx43 gap junctions, it is clear that ACT1 does not inhibit Cx43 gap junction channel activity. The accumulation of $\mathrm{Cx} 43$ gap junctions upon ACT1 treatment seems to be beneficial for wound healing in a variety of conditions (Ghatnekar et al., 2009; Gourdie et al., 2006; Rhett et al., 2008).

Very recently, ACT1 has been applied in a cryo-injury model of the left ventricle, which was proposed to be relevant for ventricular arrhythmias (O'Quinn et al., 2011). The latter has been associated with $\mathrm{Cx}_{43}$ gap junction remodeling, which also occurred in the wound and injury border zone. ACT1 exposure prevented Cx43 gap junction remodeling, thereby suppressing arrhythmic behavior of the heart and increasing ventricular depolarization rates up to 7-9 days after the injury. While control samples displayed an increased lateralization of $\mathrm{Cx} 43$ associated with $\mathrm{Cx} 43$ dephosphorylation, ACT1-treated samples displayed an improved accumulation of Cx43 at the intercalated disks. ACT1 partially prevented Cx43 dephosphorylation by increasing the PKC-epsilon-mediated phosphorylation of Ser368 of $\mathrm{Cx} 43$ at the wound and injury border zone. Interestingly, ACT1 also stimulated PKC-epsilon-mediated phosphorylation of recombinantly expressed and purified C-terminal tail of $\mathrm{Cx} 43$ in vitro, while PDZ-2 of ZO- 1 counteracted this process. These cardioprotective effects of ACT1 on Cx43 phosphorylation fits the earlier reports showing that PKC-epsilon prevented CX43 gap junction remodeling during transient ischemia (Ek-Vitorin et al., 2006) or during global ischemia after ischemic pre-conditioning (Srisakuldee et al., 2009).

\subsubsection{The $L 2$ peptide}

As discussed above, the $\mathrm{L} 2$ region in the cytoplasmic loop domain was shown to function as a receptor for the C-terminal tail (Duffy et al., 2002). Binding of the C-terminal tail to the L2 region is known to close $\mathrm{Cx} 43$ gap junction channels, like during low $\mathrm{pH}_{\mathrm{i}} /$ ischemic conditions (Duffy et al., 2002; Ek-Vitorin et al., 1996; Morley et al., 1996). Based on these findings, a peptide corresponding to the L2 region of Cx43 (amino acids 119-144) has been developed (Seki et al., 2004b) (Fig. 3). Application of this peptide did not alter the unitary conductance of $\mathrm{Cx} 43$ gap junction channels, but decreased the frequency of transitions into the residual state, increased the open time and altered the voltage dependence of the $\mathrm{Cx} 43$ gap junction channels. These effects resembled the results obtained with $\mathrm{Cx} 43^{\mathrm{M} 257}$. Furthermore, the L2 peptide was also shown to bind the $\mathrm{C}$-terminal tail of $\mathrm{Cx} 43$ at $\mathrm{pH}$ 6.5. A mutant L2 peptide (L2 $\left.{ }^{\mathrm{H} 126 \mathrm{~K} / 1130 \mathrm{~N}}\right)$ was not able to bind Cx43's C-terminal tail and did not affect $\mathrm{Cx} 43$ gap junction channel properties. These mutations, which occur in the region that corresponds to the first alpha-helix, likely disrupt the structural elements in this peptide needed for interaction with the C-terminal tail. In follow-up studies, another L2 mutant peptide was analyzed. $2^{\mathrm{H} 142 \mathrm{E}}$, which lacked the second His critical for the formation of the second alphahelix in the L2 peptide, failed to bind the C-terminal tail of $\mathrm{Cx} 43$ and modulate Cx43 gap junction channel properties in electrophysiological experiments (Shibayama et al., 2006). Thus, L2 peptides by preventing intramolecular loop/tail interactions seem to favor the open state of $\mathrm{Cx} 43$ gap junction channels in response to high transjunctional voltage $(\geq+60 \mathrm{mV})$.

\subsection{Non-Cx43-mimetic peptides modulating Cx43 gap junctions}

\subsubsection{RXP-E peptide}

An unbiased peptide screen for binding the C-terminal tail of Cx43 resulted in the identification of novel peptides that could modulate $\mathrm{Cx} 43$ gap junctions by targeting intramolecular interactions (Shibayama et al., 2006). In particular, peptides containing the RXP motif were found to preferably target the Cterminal tail of $\mathrm{Cx} 43$ (Shibayama et al., 2006). Further optimization studies resulted in an RXP-E peptide that binds the C-terminal tail of $\mathrm{Cx} 43$ with high affinity. Importantly, in electrophysiological experiments in N2a cells ectopically expressing Cx43, RXP-E 
increased the mean open time of $\mathrm{Cx} 43$ gap junction channels and partially prevented the closure of $\mathrm{Cx} 43$ gap junction channels in response to octanol or acidosis. Importantly, the effect of RXP-E on octanol-induced uncoupling of $\mathrm{Cx} 43$ gap junctions required the presence of the C-terminal tail of $\mathrm{Cx} 43$. Indeed, RXP-E was not able to alleviate the octanol-triggered uncoupling of $\mathrm{Cx} 43^{\mathrm{M} 257}$-based gap junctions, although there was a delay in octanol inhibition, suggesting an additional target outside the C-terminal tail of $\mathrm{Cx} 43$. NMR studies led to the identification of two RXP-E-binding regions in the C-terminal tail of $\mathrm{Cx} 43$, covering amino acids 343 to 346 (region 1) and 376-379 (region 2) (Shibayama et al., 2006). Importantly, region 1 has been found to be important for $\mathrm{pH}-$ dependent dimerization of the C-terminal tail of $\mathrm{Cx} 43$ (Sorgen et al., 2004b), while region 2 was identified as the PDZ-2-binding site of ZO-1 (Sorgen et al., 2004a). Thus, RXP-E peptide might be very potent, since it displays two separate molecular and biological properties, thereby interfering with intramolecular interactions underlying C-terminal tail dimerization and with intermolecular interactions underlying the recruitment of ZO-1. The effects of RXP$\mathrm{E}$ were further assessed in monolayer cultures of cardiomyocytes isolated from neonatal and adult rats (Lewandowski et al., 2008), revealing that RXP-E i) was able to bind the cardiac $\mathrm{Cx} 43$, ii) alleviated $\mathrm{Cx} 43$ gap junction uncoupling upon heptanol and intracellular acidosis, and iii) prevented the block of action potential propagation upon intracellular acidosis. Further work resulted in the development of two novel pharmacophores, a cyclized heptapeptide (called CyRP-71) and a linear octapeptide of sequence RRNYRRNY, promoting Cx43 gap junction channel opening (Verma et al., 2009). The identification of the core structural elements in the RXP-E peptide (RRXY) has spurred the development of the first peptidomimetic molecule, AcRRK(4-HO-Benzoyl)-NH2, called ZP2519, that prevented the closure of Cx43 gap junctions upon heptanol exposure or intracellular acidosis by targeting the C-terminal tail of Cx43 (Verma et al., 2010).

\subsection{2. $A A P 10$ and $Z P 123$}

About twenty years ago, a synthetic peptide called AAP10 (GAG-4Hyp-PY-CONH ${ }_{2}$ ) was found to display anti-arrhythmic effects (Dhein et al., 1994) and this could be linked to effects on Cx43 expression and function via a PKC-dependent mechanism (De Vuyst et al., 2011; Easton et al., 2009; Hagen et al., 2009; Herve and Dhein, 2006). AAP10 is based on the natural anti-arrhythmic peptide AAPnat (H-Gly-Pro-Hyp-Gly-Ala-Gly) that was isolated from bovine atria and further synthetically improved (Dhein et al., 1994; Grover and Dhein, 2001). Application of AAP10 (even at very low concentration of 10 and $50 \mathrm{nM}$ ) enhanced gap junction conductance in adult guinea pig cardiomyocytes, which are predominantly coupled via $\mathrm{Cx} 43$ and in HeLa cells ectopically expressing Cx43 (Weng et al., 2002). The stimulatory effect of AAP10 on gap junction conductance was dependent on PKCalpha activity. AAP10 enhanced the activity of PKCalpha, thereby promoting PKCalpha-dependent phosphorylation of $\mathrm{Cx} 43$. These peptides were further used to counteract $\mathrm{Cx} 43$ gap junction remodeling in heart failure models. For instance, acute hypoxia in rat hearts leads to a decrease in $\mathrm{Cx} 43$ expression, reduced $\mathrm{Cx} 43$ phosphorylation and redistribution of $\mathrm{Cx} 43$ from gap junctions into intracellular pools, resulting in decreased gap junction communication (Wang et al., 2007). AAP10 prevented Cx43 dephosphorylation during acute hypoxia and increased total $\mathrm{Cx} 43$ levels (mainly in the phosphorylated form), thereby preventing shut down of gap junction communication in the heart. In acute regional myocardial ischemia, AAP10 prevented the decrease in Cx43 phosphorylation in the ischemic region, but had no effect on Cx43 phosphorylation in the non-ischemic region (Jozwiak and Dhein, 2008). The decrease in $\mathrm{Cx} 43$ phosphorylation was associated with $\mathrm{Cx} 43$ redistribution in the ischemic zone, which could be prevented by AAP10 treatment. However, peptides based on L-amino acids display a poor stability in in vivo systems. Therefore, a new anti-arrhythmic peptide was developed, ZP123 (rotigapeptide), representing a retro-all-D-amino acid design of the AAP10 template (Ac-D-Tyr-D-Pro-D-4Hyp-Gly-D-Ala-Gly$\mathrm{NH}_{2}$ ) (Dhein et al., 2003; Wit and Duffy, 2008). ZP123 too enhanced $\mathrm{Cx} 43$ gap junction conductance in a PKCalphadependent manner, but with enhanced enzymatic stability in in vivo applications. Consistent with its positive effect on gap junction conductance, rotigapeptide also prevented the closure of gap junction channels by acidosis (Eloff et al., 2003), thereby maintaining intercellular coupling, diminishing the slowing down of conduction velocity and the heterogeneity in repolarization. All these influences contribute to anti-arrhythmic effects. Rotigapeptide also preserved the conduction of the atria during metabolic stress (Haugan et al., 2005) and upon atrial fibrillation (Guerra et al., 2006; Shiroshita-Takeshita et al., 2007). In open-chest dogs undergoing ischemia/reperfusion and rats with chronic myocardial infarction, spontaneous arrhythmias and infarct size were reduced by rotigapeptide treatment (Haugan et al., 2006; Hennan et al., 2006). Again, these effects likely are due to maintained Cx43 phosphorylation (e.g. at Ser297 and Ser368), which is indeed to form functional gap junction channels (Axelsen et al., 2006). Interestingly, rotigapeptide has been applied to explanted heart from end-stage heart failure patients and resulted in an improved conduction velocity (Wiegerinck et al., 2009). However, in healing infarct border zone partial reversal of $\mathrm{Cx} 43$ remodeling seemed not be sufficient to restore normal conduction or prevent arrhythmias (Macia et al., 2011).

\section{Intramolecular loop/tail interactions are essential for Cx43-hemichannel opening}

3.1. Cx43 hemichannels and gap junction channels display opposite outcomes to signaling molecules

There is increasing evidence from several labs that gap junctions and hemichannels may be influenced in an opposite manner by signaling molecules or intracellular events. For instance, it is well established that metabolic inhibition associated with ischemia/reperfusion lead to closure of $\mathrm{Cx} 43$ gap junction channels in the heart (Duffy et al., 2004; Johansen et al., 2011; Severs, 1994), while promoting the opening of Cx43 hemichannels, resulting in ionic leakage, intracellular $\mathrm{Ca}^{2+}$ and $\mathrm{Na}^{+}$overload and cell death (Johansen et al., 2011; John et al., 1999; Kondo et al., 2000; Li et al., 2001; Shintani-Ishida et al., 2007). Cytokines, like interleukin-1beta and tumor necrosis factor-alpha are released by microglia under inflammatory conditions (Kettenmann et al., 2011; Simi et al., 2007) inhibit Cx43 gap junctions, thereby reducing intercellular communication between astrocytes while enhancing Cx43-hemichannel activity, thereby increasing plasma membrane permeability (Retamal et al., 2007a). The latter is based on strong evidence using Cx43-knockout mice and Cx43hemichannel inhibitors. Interestingly, opposite functional outcomes of cytokines on Cx43 gap junctions and hemichannels were mediated by a common p38 mitogen activated protein kinase pathway. The effects of cytokines on Cx43 hemichannels were dependent on sulfhydryl oxidation reactions on $\mathrm{Cx} 43$, since reducing agents like dithiothreitol counteracted these effects. Moreover, these cytokines also resulted in increased Cx43hemichannel activity, despite the reduction in the total and surface-available Cx43 levels upon cytokine treatment. The latter finding is supported by electrophysiological experiments showing that the unitary events of $\sim 220 \mathrm{pS}$ corresponding to $\mathrm{Cx} 43$ 
hemichannels were much more frequent in cytokine-treated astrocytes. Other studies found similar oppositely directed effects on gap junctions and hemichannels. For instance, an augmented level of intracellular oxidative stress (e.g. during ischemia/reperfusion) decreased Cx43-mediated gap junction communication, but at the same time increased $\mathrm{Cx}$ 43-hemichannel activity by increasing the open probability and the number of surface $\mathrm{Cx} 43$ hemichannels (Retamal et al., 2006, 2007b, c). Again, this mechanism seemed to depend on changes in the intracellular redox state, which may modulate $\mathrm{Cx} 43$ hemichannels by influencing the three intracellular Cys residues present on the C-terminal tail. In C6 glioma cells ectopically expressing Cx43, some kinase-activating stimuli, like the immunostimulating lipopolysaccharide (LPS) and basic fibroblast growth factor (bFGF), have been described to cause the inhibition of $\mathrm{Cx} 43$ gap junction channels, while stimulating the release of ATP via Cx43 hemichannels (De Vuyst et al., 2007). An independent study from Saez and co-workers clearly underpinned these findings, showing that fibroblast growth factor-1 (FGF-1), which is released in spinal cord injury, caused permeabilization and ATP release of spinal cord astrocytes (Garre et al., 2010). This ATP release was at least in part through the opening of $\mathrm{Cx} 43$ hemichannels (besides vesicular ATP release and Panx-mediated ATP release). In contrast, interastrocyte coupling through $\mathrm{Cx} 43$ gap junctions was inhibited. These mechanisms may further promote inflammation and to contribute to the loss of protective effects of astrocytes on neurons. In any case, there seems ample evidence that Cx43-based gap junction channels and hemichannels are oppositely regulated, as recently highlighted by the differential action of growth factors on gap junctions and hemichannels (Schalper et al., 2012).

\subsection{Loop and C-terminal tail modifications differentially affect Cx43 gap junctions and hemichannels}

Besides the evidence at the physiological level that Cx43-based gap junction channels and hemichannels display opposite responses upon cellular signaling events, there are also a number of molecular studies exploiting the expression of truncated, Cterminally tagged or mutated $\mathrm{Cx} 43$ proteins (Fig. 4). These studies point towards critical differences in the dependence of gap

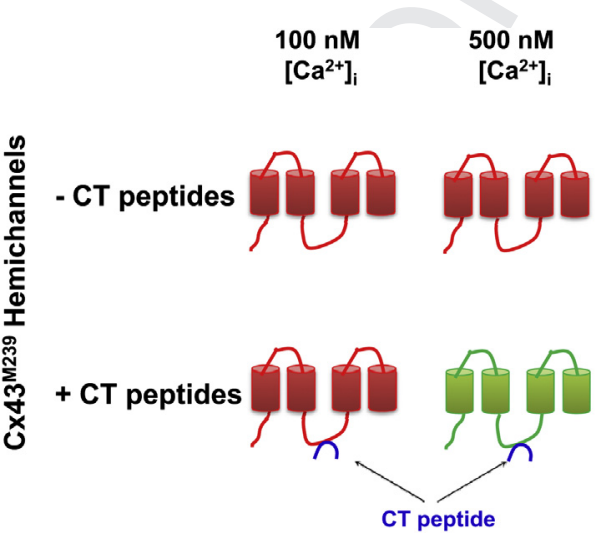

Fig. 4. TAT-CT10 is sufficient to restore the activity of C-terminally truncated $\mathrm{Cx} 43$ hemichannels. C-terminally truncated $\mathrm{Cx} 43$ hemichannels cannot be opened in response to stimuli like an increase in intracellular $\left[\mathrm{Ca}^{2+}\right]$. Yet, the addition of the last 10 amino acids is sufficient to open C-terminally truncated Cx43 hemichannels in response to an increase in intracellular $\left[\mathrm{Ca}^{2+}\right]$. It is important to note that the peptide by itself is not sufficient to open the C-terminally truncated Cx43 hemichannels in the absence of stimuli. For clarity reasons, the monomeric building blocks are depicted, but it should be noted that the functional channel unit is hexameric. junction channels versus hemichannels to intramolecular loop/tail interactions for their activity. i) C-terminally truncated Cx43 is able to form functional gap junction channels (De Vuyst et al., 2007; Maass et al., 2007), which are even resistant to closure upon intracellular acidosis (Morley et al., 1996). In contrast, Cterminally truncated $\mathrm{Cx} 43$ hemichannels fail to form functional hemichannels. The latter is supported by different types of evidence. In electrophysiological experiments using cell-attached patches and inside-out patches on C6 glioma cells ectopically expressing $\mathrm{Cx} 43$, the opening of $\mathrm{Cx} 43$ hemichannels could be detected and analyzed (Kang et al., 2008). However, truncating Cx43 at Met257 resulted in loss of Cx43 hemichannel activity and single-channel openings were not observed. This is further supported by other studies, showing that cells ectopically expressing $\mathrm{Cx} 43^{\mathrm{M} 239}$ or $\mathrm{C} \times 43^{\mathrm{M} 257}$ display strongly reduced ATP release triggered by decreasing extracellular $\left[\mathrm{Ca}^{2+}\right]$ using the $\mathrm{Ca}^{2+}$ buffer EGTA (De Vuyst et al., 2007) or by increasing intracellular $\left[\mathrm{Ca}^{2+}\right]$ using the $\mathrm{Ca}^{2+}$ ionophore A23187 (De Vuyst et al., 2009; Ponsaerts et al., 2010) (Fig. 4). ii) GFP-tagging of $\mathrm{Cx} 43$ at its C-terminal tail resulted in an increase of the gap junction-plaque size, and a potentiation of gap junction communication (Bukauskas et al., 2000; Hunter et al., 2003; Verselis and Bukauskas, 2002). Cx43GFP-based hemichannels displayed altered gating. For instance, they only displayed slow gating between the fully closed and the fully open state while the fast gating from the residual state to the fully open state disappeared (Contreras et al., 2003; Kang et al., 2008). These data correlate with the compromised ATP-flux properties of Cx43-GFP-based hemichannels (Kang et al., 2008). Yet, brief openings of the Cx43 hemichannels might occur as ethidium bromide uptake was observed in Cx43-GFP-expressing cells (Contreras et al., 2003). The latter has been confirmed in studies showing that lowering the intracellular redox potential or exposing cells to FGF-1 promotes the opening of $\mathrm{Cx} 43$ and $\mathrm{Cx} 43$ EGFP-based hemichannels (Retamal et al., 2007b; Schalper et al., 2008). In any case, the influence of GFP tagged to the C-terminal tail of $\mathrm{Cx} 43$ on endogenous loop/tail interactions in Cx43 hemichannels ought to be further established. iii) Pathological mutations in the L2 region of $\mathrm{Cx} 43$ have been identified in patients suffering from oculodentodigital dysplasia. For instance, $\mathrm{Cx} 43^{\mathrm{G} 138 \mathrm{R}}$ and $\mathrm{Cx} 43^{\mathrm{G} 143 \mathrm{~S}}$ were found to be deficient in gap junction coupling, while ATP-releasing hemichannel activity was promoted (Dobrowolski et al., 2007). Hence, these mutations, which occur in the $\mathrm{L} 2$ region, differentially affect $\mathrm{Cx} 43$ gap junctions and hemichannels. Thus, these data indicate that while $\mathrm{Cx} 43$ gap junctions are closed by intramolecular loop/tail interactions, e.g. during intracellular acidosis (Ek-Vitorin et al., 1996), Cx43 hemichannels actually depend on intramolecular loop/tail interactions for their opening in response to cellular stimuli (Ponsaerts et al., 2010). Yet, at this stage, it is not clear whether these intramolecular loop/tail interactions in $\mathrm{Cx} 43$ hemichannels are pre-established (even in the absence of cellular stimuli) or whether stimuli that increase Cx43-hemichannel opening (like depolarization, low extracellular $\left[\mathrm{Ca}^{2+}\right]$ or moderate rises in intracellular $\left.\left[\mathrm{Ca}^{2+}\right]\right)$ do it by triggering the binding of the $\mathrm{C}$-terminal tail to the intracellular loop. It is thus conceivable that these cellular stimuli trigger conformational changes in the $\mathrm{Cx}$ 43-building blocks that facilitate the binding and subsequent opening of the $\mathrm{Cx} 43$ hemichannels or that only the conformation of $\mathrm{Cx} 43$ hemichannels in which loop/tail interactions are established allows to sense the stimuli, resulting in the opening of $\mathrm{Cx} 43$ hemichannels. The latter option definitely is possible, since we found that the $\mathrm{L} 2$ region was able to bind the $\mathrm{C}$ terminal tail of $\mathrm{Cx} 43$ at physiological pH (Ponsaerts et al., 2010). In any case, we postulate that the binding of the C-terminal tail to the intracellular loop is not sufficient for the opening of Cx43 hemichannels, but requires an additional activating stimulus. 
3.3. Intracellular loop peptides inhibit $C \times 43$ hemichannels but not gap junction channels

As discussed above, the $\mathrm{L} 2$ region in $\mathrm{Cx} 43$ acts as a receptor for the C-terminal tail, which functions as a gating particle, underlying the closure of gap junction channels during acidosis (Duffy et al., 2002; Seki et al., 2004b). Synthetic L2 peptides promote the opening of Cx43 gap junction channels (Duffy et al., 2002; Seki et al., 2004b; Shibayama et al., 2006). Making use of the cellpermeable TAT-coupled L2 peptide, we found that the L2 peptide inhibited the opening of $\mathrm{Cx} 43$ hemichannels in response to an extracellular $\left[\mathrm{Ca}^{2+}\right]$ decrease or an intracellular $\left[\mathrm{Ca}^{2+}\right]$ increase without affecting gap junction coupling (Evans et al., 2012; Ponsaerts et al., 2010) (Figs. 1 and 3). TAT-L2 inhibited Cx43hemichannel-mediated ATP release in response to a $\left[\mathrm{Ca}^{2+}\right]$ increase brought about by $2 \mu \mathrm{M} \mathrm{Ca}^{2+}$ ionophore with an IC50 of about $10 \mu \mathrm{M}$. Further studies led to the identification of a nonapeptide variant of L2 peptide that displayed a certain degree of endogenous cell-penetrating potential (Gap19) (Evans et al., 2012; Wang et al., 2013b) (Fig. 3). The Gap19 peptide covers the region between amino acids 128 and 136. Gap19 provoked Cx43hemichannel inhibition with an IC50 of about $50 \mu \mathrm{M}$, while not blocking Cx43 gap junction channels (Wang et al., 2013b). Coupling Gap19 to TAT facilitated its cell-penetrating properties and provoked inhibition of $\mathrm{Cx} 43$-hemichannel responses with an IC50 of less than $10 \mu \mathrm{M}$. Furthermore, Gap19 was selective for Cx43-based hemichannels, since it had no effect on Cx40- and Panx1-based hemichannels. These findings were supported by electrophysiological experiments, demonstrating that Gap19 inhibit Cx43 hemichannel unitary currents in both HeLa cells exogenously expressing $\mathrm{Cx} 43$ and acutely isolated pig ventricular cardiomyocytes. Thus, Gap19 inhibition of Cx43 hemichannel opening, activated by voltage, is likely the result of a shift of the activation potential of hemichannel opening to more positive potentials. Consistent with previous reports, we found that biotinylated versions of L2 and Gap19 were able to bind the C-terminal tail of $\mathrm{Cx} 43$, expressed and purified as a recombinant protein, in surface plasmon resonance experiments (Wang et al., 2013b). Thus, it seems that the binding of the C-terminal tail of Cx43 hemichannels to its endogenous L2 receptor region in $\mathrm{Cx} 43$ is an absolute requirement for the opening of $\mathrm{Cx} 43$ hemichannels. Preventing this binding using TAT-L2 or Gap19 resulted in the inhibition of Cx43-hemichannel opening. Furthermore, a stretch of nine amino acids within the L2 region seem to serve as a hot spot for the interaction of the C-terminal tail, carrying critical elements for intramolecular loop/tail-complex formation. Interestingly, the amino acids present in Gap19 are largely positively charged (KQIEIKKFK), thereby contributing to its intrinsic cell-penetrating properties. Critical amino acids in Gap19 were I130 and K134, since mutating these residues into Ala disrupted its ability to inhibit Cx43 hemichannels. The influence of K134A mutation on Gap19 function was tested in a mammalian expressing plasmid encoding Flag-Gap19. The critical role of K134 fits well with the presumed binding site at the C-terminal tail, namely the last nine amino acids, in which negatively charged Asp residues have been implicated in establishing loop/tail binding via ionic interactions (Hirst-Jensen et al., 2007). Additionally, the critical role of I130 in Gap19 in the inhibition of Cx43 hemichannels fits well with presumed structural integrity that is needed at this site to form alphahelical structures (Duffy et al., 2002). In addition, I130 may contribute to the binding of the C-terminal tail via non-ionic interactions. Consistent with these findings, Gap19 $19^{\mathrm{I} 130 \mathrm{~A}}$ was much less efficient in inhibiting Cx43 hemichannel unitary currents in Cx43-expressing HeLa cells and adult pig cardiomyocytes containing endogenous high levels of Cx43 (Wang et al., 2013b).
Finally, since cell-penetrating Cx43-loop peptides selectively inhibit Cx43 hemichannels without blocking Cx43 gap junction channels, they are ideal tools to target $\mathrm{Cx} 43$ hemichannels in complex cellular systems or to demonstrate the contribution of Cx43 hemichannels in cellular signaling processes (Evans et al., 2012). In particular, traditional knockout or knockdown approaches prevent the expression of the $\mathrm{Cx} 43$ building blocks, thereby affecting both Cx43 gap junction and hemichannels. As a control for TAT-L2, it is recommended to use TAT-L2 ${ }^{\mathrm{H} 126 \mathrm{~K} / 1130 \mathrm{~N}}$, a mutated version of TAT-L2 that is not able to bind the C-terminal tail of $\mathrm{Cx} 43$ and thus does not interfere with loop/tail interactions.

\subsection{C-terminal tail peptides restore the activity of $\mathrm{C} \times 43^{\mathrm{M} 239}$ hemichannels}

As discussed above, $\mathrm{C} \times 43^{\mathrm{M} 239}$ hemichannels fail to open in response to conditions that stimulate $\mathrm{Cx} 43$-hemichannel opening. Strikingly, we found that a short peptide sequence covering the last 10 amino acids of the C-terminal tail (TAT-CT10) was sufficient to restore the activity of $\mathrm{Cx} 43$ hemichannels that lack their complete C-terminal tail (Ponsaerts et al., 2010). This was supported by ATP release assays in $\mathrm{Cx} 43^{\mathrm{M} 239}$-expressing $\mathrm{C} 6$ glioma and HeLa cells. Further evidence was provided by electrophysiological measurements in Xenopus oocytes, in which endogenous Cx38 was knocked down and ectopic Cx43 was expressed (Ponsaerts et al., 2010). Consistent with the original report showing that in Xenopus oocytes expression of $\mathrm{Cx}_{4} 43$, in contrast to $\mathrm{Cx} 46$, does not induce depolarization, lysis, permeability to Lucifer yellow and voltage-gated currents in non-junctional membranes (Paul et al., 1991), we confirmed that $\mathrm{Cx} 43$ is not able to form functional hemichannels in Xenopus oocytes (Ponsaerts et al., 2010). We have proposed that the strong cortical actin cytoskeleton prevents the binding of the Cterminal tail to the cytoplasmic loop domain, thereby hampering the opening of Cx43 hemichannels (Ponsaerts et al., 2012b). Strikingly, TAT-CT10 was able to overcome this inherent lack of loop/tail interactions, thereby restoring the activity of $\mathrm{Cx} 43$ hemichannels as determined in electrophysiology experiments in Xenopus oocytes exogenously expressing Cx43 (Ponsaerts et al., 2010). The negative regulation of $\mathrm{Cx} 43$-hemichannel activity by the actin cytoskeleton via disrupting essential loop/tail interactions has been further underpinned by a variety of experimental approaches. Thrombin treatment of corneal endothelial cells inhibits Cx43-hemichanneldriven intercellular $\mathrm{Ca}^{2+}$-wave propagation via the cytoskeleton, since (-)-blebbistatin could alleviate this inhibitory effect (Ponsaerts et al., 2008). Pre-incubating corneal endothelial cells with TAT-CT10 completely alleviated thrombin-induced inhibition of Cx43 hemichannels (Ponsaerts et al., 2010). Similarly, C6 or HeLa cells ectopically expressing $\mathrm{Cx} 43$ display a bell-shaped dependence towards intracellular $\left[\mathrm{Ca}^{2+}\right]$, with $\left[\mathrm{Ca}^{2+}\right]$ below $500 \mathrm{nM}$ triggering Cx43-hemichannel opening and with $\left[\mathrm{Ca}^{2+}\right]$ above $500 \mathrm{nM}$ inhibiting Cx43-hemichannel opening (De Vuyst et al., 2009). The inhibition of $\mathrm{Cx} 43$ hemichannels by high intracellular $\left[\mathrm{Ca}^{2+}\right]$ could be completely alleviated by (-)-blebbistatin (Ponsaerts et al., 2010). In contrast, pre-incubating the cells with TAT-CT10 completely prevented the inhibition of $\mathrm{Cx} 43$ hemichannels by high intracellular $\left[\mathrm{Ca}^{2+}\right]$ (Ponsaerts et al., 2010). Correlating with this, TAT-CT10 restored the activity of $\mathrm{Cx} 43^{\mathrm{M} 239}$ hemichannels, while (-)-blebbistatin did not. Thus, it seems that the last 10 amino acids of the Cterminal tail harbor residues that are critical for loop/tail interactions in $\mathrm{Cx} 43$ hemichannels. Hence, these findings reinforce the necessity for the C-terminal tail of $\mathrm{Cx} 43$ for $\mathrm{Cx} 43$-hemichannel activity (Ponsaerts et al., 2010). Moreover, these effects of TAT-CT10 were independent of its ability to bind the PDZ-2 domain of ZO-1. Indeed, TAT-CT10 $\Delta \mathrm{I}$, lacking the last isoleucine residue essential for the binding of the PDZ-2 domain of ZO-1 (Giepmans and 
Moolenaar, 1998), was equally potent in i) restoring the activity of $\mathrm{Cx} 43^{\mathrm{M} 239}$-based hemichannels and ii) alleviating the inhibition of Cx43-based hemichannels by high intracellular $\left[\mathrm{Ca}^{2+}\right]$ (Ponsaerts et al., 2010). At the biochemical level, we demonstrated that a biotinylated version of CT10 and CT10دI was able to interact with the $\mathrm{L} 2$ region of $\mathrm{Cx} 43$ but not with the $\mathrm{L} 2^{\mathrm{H} 126 \mathrm{~K} / \mathrm{I} 130 \mathrm{~N}}$ variant (Ponsaerts et al., 2010). Finally, while CT10 binding to L2 is required for the opening of $\mathrm{Cx} 43$ hemichannels, it is not sufficient by itself to induce Cx43-hemichannel opening (Ponsaerts et al., 2010). Indeed, TAT-CT10, by itself, did not open $\mathrm{Cx} 43^{\mathrm{M} 239}$ hemichannels in the absence of stimuli like low extracellular $\left[\mathrm{Ca}^{2+}\right]$ or increased intracellular $\left[\mathrm{Ca}^{2+}\right]$.

Very recently, we identified the residues in TAT-CT10 critical for its activity to regulate CX43 hemichannels (D'hondt et al., 2013). We found that mutating Asp378 and Asp379 into Ala residues abolished TAT-CT10's ability to alleviate the inhibition of Cx43 hemichannels by high intracellular $\left[\mathrm{Ca}^{2+}\right]$ and to restore $\mathrm{Cx} 43^{\mathrm{M} 239}$ hemichannel activity in response to moderate rises in intracellular $\left[\mathrm{Ca}^{2+}\right]$. Similar results were obtained by mutating Pro375 and Pro377 into Gly residues. On the other hand, mutating Arg374 and Arg376 into Ala residues did not alter the functional properties of TAT-CT10 on Cx43 hemichannels. Thus, it seems that at least negatively charged Asp residues and their proper structural organization via Pro residues are critical determinants to establish loop/ tail interactions involving the CT10 region.

\subsection{Cell-permeable loop peptides and C-terminal tail peptides neutralize each other's action}

Finally, the inhibition of $\mathrm{Cx} 43$ hemichannels by TAT-L2 or Gap19 can be completely neutralized by co-incubating the cells with TATCT10 (Ponsaerts et al., 2010; Wang et al., 2013b). Consistent with the importance of ionic and non-ionic interactions, the neutralization of Gap19's inhibitory properties on Cx43 hemichannels by TAT-CT10 was dependent on the presence of two Pro residues (amino acids 375 and 377) and two Asp residues (amino acids 378 and 379) (Wang et al., 2013b). The importance of these residues in the CT10 sequence for binding the cytoplasmic loop domain ought to be further examined in in vitro binding experiments, like surface plasmon resonance. Vice versa, the ability of TAT-CT10 to overcome the inhibition of $\mathrm{Cx} 43$ hemichannels in response to high intracellular $\left[\mathrm{Ca}^{2+}\right]$ is ablated by co-incubating the cells with TAT-L2 (Ponsaerts et al., 2010). These findings are mechanistically supported by the ability of biotin-CT10 immobilized to a streptavidincoated sensor chip to bind TAT-L2 in in vitro binding experiments based on surface plasmon resonance.

\subsection{Applications of cell-permeable loop and C-terminal tail peptides to tackle Cx43 hemichannel functions in complex cellular systems and pathophysiological conditions}

\subsection{1. $L 2$}

There has been increasing evidence from in vitro and ex vivo studies that astrocytes are involved in synaptic plasticity and may contribute to synaptic activity via the release of neuroactive gliotransmitter substances, including D-serine, glutamate, and ATP (Fellin et al., 2006; Scolari and Acosta, 2007; Verkhratsky and Parpura, 2010; Volterra and Meldolesi, 2005). In addition, glutamate released from astroglial cells has been shown to affect neurotransmitter release at the synaptic cleft (Santello et al., 2012). Unfortunately, due to the lack of selective Cx43-hemichannel inhibitors and the fact that $\mathrm{Cx} 43$-knockout animals lack both gap junction channels and hemichannels, the role of Cx43 hemichannels in the release of gliotransmitters from astrocytes and their relevance for the control of higher brain function in vivo is still an open question (Stehberg et al., 2012). Recently, we exploited the biophysical properties of TAT-L2 to assess whether Cx43 hemichannels are involved in the release of gliotransmitters under in vivo conditions. This approach was possible because this peptide did not affect the neuronal components of synaptic transmission, which do not express $\mathrm{Cx} 43$, nor did the peptide influence gap junction coupling between neighboring astrocytes. The TAT-L2 peptide was micro-injected in the basolateral amygdala, a region of the brain involved in the processing of emotion, more specifically fear and fear memory (Stehberg et al., 2012). Using an auditory fear conditioning training protocol (a conditioned sound stimulus shortly followed by an unconditioned electrical shock stimulus), proper memory consolidation was assessed $24 \mathrm{~h}$ after the training by providing the conditioned sound stimulus only (Stehberg et al., 2012). Strikingly, TAT-L2, but not TAT-L2 ${ }^{\mathrm{H} 126 \mathrm{~K} / 1130 \mathrm{~N}}$, completely and potently blocked fear memory consolidation and provoked a complete amnesia towards the auditory fear conditioning. Concentrations as low as $10 \mathrm{nM}$ TAT-L2 proved to be effective in triggering amnesia. These effects of TAT-L2 were transitory and did not affect the short-term memory aspects of the fear conditioning paradigm. Also, the amnesic effects of TAT-L2 were only provoked when administered during the period of memory consolidation (within the first $4 \mathrm{~h}$ after the auditory fear conditioning training protocol). Moreover, inhibition of fear memory by TAT-L2 disappeared by supplementing TAT-L2 with an exogenous cocktail of putative gliotransmitters (including glutamate, glutamine, lactate, D-serine, glycine, and ATP). These data demonstrate the potential of TAT-L2 as a tool to help unraveling the contribution of $\mathrm{Cx} 43$ hemichannels in complex biological systems like the brain.

\subsubsection{Gap19}

Gap19 is a nonapeptide variant of TAT-L2 that displays intrinsic cell-penetrating activities and selectively inhibits Cx43 hemichannels (Fig. 2) (Evans et al., 2012; Wang et al., 2013b). Importantly, Gap19 $(100 \mu \mathrm{M})$ strongly inhibited unitary Cx43hemichannel currents in freshly isolated cardiomyocytes (Wang et al., 2013b). Moreover, Gap19 also inhibited the promotion of unitary hemichannels currents when the cardiomyocytes were subject to metabolic inhibition by applying a combination of mitochondrial uncoupler and a glycolysis inhibitor (chemical inhibition) (Wang et al., 2013b). This was further tested both in vitro and in vivo in ischemia, which is known to promote deleterious Cx43-hemichannel activity in a redox and phosphorylationdependent manner (Wang et al., 2013b). In those experiments, it was hypothesized that excessive opening of $\mathrm{Cx} 43$ hemichannels results in cell death due to the loss of energy, ionic and metabolic gradients (Evans et al., 2006). In freshly isolated cardiomyocytes, addition of Gap19 before exposure to oxygen-glucose deprivation/ acidosis followed by reperfusion, improved the cell viability and prevented cell swelling (Wang et al., 2013b). Importantly, Gap19 ${ }^{1130 A}$ was much less potent than Gap19 in suppressing cell death and swelling. Finally, in in vivo myocardial ischemia/reperfusion applied to mice by ligation of the left anterior descending coronary artery followed by reperfusion, Gap19, but not Gap191130A ( $250 \mu \mathrm{M}$, added $10 \mathrm{~min}$ before ligation), significantly reduced the infarct size. These are promising observations, indicating that the opening of $\mathrm{Cx} 43$ hemichannels in the plasma membrane may indeed contribute to ischemia/reperfusion damage in the heart. It is essential here to underscore the fact that gap junction channels are not inhibited by Gap19; in the heart but also in the brain, inhibition of gap junctions would result in significant confounding effects, making interpretation of the experimental results problematic. Hence, Gap19 inhibition of Cx43 hemichannels, combined with work on the $\mathrm{Cx} 43^{\mathrm{G} 138 \mathrm{R}}$ mutant that is linked to promoted hemichannel activity (Dobrowolski et al., 2007) offers an interesting set 
of tools to explore the role of $\mathrm{Cx} 43$ hemichannels in various physiological and pathological conditions. Moreover, Gap19 and L2 peptides not only have specificity toward hemichannels, but also toward the specific type of $\mathrm{Cx}$. Indeed, the sequences mimicked by these peptides are located on the cytoplasmic loop of the $\mathrm{Cx}$ protein; these sequences are very different between different $C x$ types. In line with this, we found that Gap19 blocked Cx43 hemichannels but not those composed of Cx40 or Panx1 (Wang et al., 2013b).

\subsubsection{CT peptides}

TAT-CT10 is a cell-permeable peptide that corresponds to the last 10 amino acids of the C-terminal tail of $\mathrm{Cx} 43$ and prevents the inhibition of $\mathrm{Cx} 43$ hemichannels by high intracellular $\left[\mathrm{Ca}^{2+}\right]$ (Ponsaerts et al., 2010). This correlates with previous findings showing that the high intracellular $\left[\mathrm{Ca}^{2+}\right]$-mediated inhibition of Cx43 hemichannels can be alleviated by using i) TAT-CT10 I, which lacks the last isoleucine (Ponsaerts et al., 2010) or ii) the CT9 peptide, which corresponds to the last 9 amino acids of the C-terminal tail and does not contain Ser373 (De Bock et al., 2012). CT9 is not cell-permeable and ought to be loaded in intact cells via other means, like electroporation approaches (De Vuyst et al., 2008) or cationic lipid-mediated transfer. Furthermore, it is important to note that ACT1, developed by Gourdie and co-workers, corresponds to the CT9 sequence, but linked to a different cell-penetrating motif that is based on the antennapedia sequence (Hunter et al., 2005; O'Quinn et al., 2011). Thus, TAT-CT10, CT9 and ACT1 converge by sharing the last 9 amino acids of the C-terminal tail of $\mathrm{Cx} 43$, harboring the critical elements for binding the $\mathrm{L} 2$ region in $\mathrm{Cx} 43$ hemichannels. Table 1 provides an overview of the sequences of these peptides.

Recently, CT9 has been used to assess the contribution of Cx43 hemichannels to sustain agonist-induced $\mathrm{Ca}^{2+}$ oscillations (De Bock et al., 2012). It was found that $\mathrm{Ca}^{2+}$ oscillations triggered by bradykinin, but not those triggered by extracellular ATP, were dependent on $\mathrm{Cx}$ hemichannels. These two agonists, and the associated two different $\mathrm{Ca}^{2+}$ oscillation mechanisms and patterns, appeared to also have a differential effect on the permeability of blood-brain barrier endothelial cells, with bradykinin increasing the permeability and ATP having no effect (De Bock et al., 2011). Using CT9 peptide and other peptides mimicking extracellular loop domains (Gap26 and/or Gap27), it was found that i) $\mathrm{Ca}^{2+}$ entry via $\mathrm{Cx} 43$ hemichannels is essential in bradykinin-triggered $\mathrm{Ca}^{2+}$ oscillations, and ii) the bell-shaped dependence of $\mathrm{Cx} 43$ hemichannels to intracellular $\left[\mathrm{Ca}^{2+}\right]$ is critical sustain $\mathrm{Ca}^{2+}$ oscillations. Thus, $\mathrm{Ca}^{2+}$ signals from the ER will rise cytosolic $\left[\mathrm{Ca}^{2+}\right]$ above $100 \mathrm{nM}$, thereby opening Cx43 hemichannels and providing a $\mathrm{Ca}^{2+}$ influx pathway (De Vuyst et al., 2009). As a result, cytosolic $\left[\mathrm{Ca}^{2+}\right]$ will further rise till $500 \mathrm{nM}$ and higher, which will lead to the closure of $\mathrm{Cx} 43$ hemichannels and closure of the $\mathrm{Ca}^{2+}$ entry pathway. It is interesting to note that $\mathrm{IP}_{3} \mathrm{Rs}$ too display a bell-shaped dependence to intracellular $\left[\mathrm{Ca}^{2+}\right]$ in the similar range as for $\mathrm{Cx} 43$ hemichannels, with low cytosolic $\left[\mathrm{Ca}^{2+}\right]$ being stimulatory and high cytosolic $\left[\mathrm{Ca}^{2+}\right]$ being inhibitory (Bezprozvanny et al., 1991; Iino, 1990). Finally, consistent with our previous findings showing that interactions between the CT peptides and the $\mathrm{L} 2$ region were independent of the last isoleucine and that inhibition of $\mathrm{Cx} 43$ hemichannels too could be alleviated by TAT-CT10 $\Delta$ I (Ponsaerts

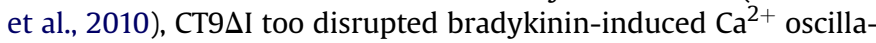
tions (De Bock et al., 2012). Thus, the effects of the CT peptides on $\mathrm{Ca}^{2+}$ oscillations are not due to the disruption of Cx43/ZO-1 interactions. In fact, $\mathrm{ZO}-1$ may mainly bind to $\mathrm{Cx} 43$ gap junctions and not hemichannels, as we failed to detect ZO-1 co-immunoprecipitation with Cx43 hemichannels (Ponsaerts et al., 2010).

\subsubsection{Therapeutic applications for selective Cx43-hemichannel} inhibitors

Definitely, given the emerging role of $\mathrm{Cx} 43$ in the spreading of cell death (Decrock et al., 2009a,b, 2011, 2012), TAT-L2 and derived peptides (like Gap19) and other small inhibitory molecules have therapeutic potential in ischemia/reperfusion injury in the brain or heart. They may reduce tissue damage from excessive cell death and its spread, by limiting excessive Cx43-hemichannel opening, while maintaining gap junction coupling. Importantly, Gap19 reduced the detrimental outcome of ischemia/reperfusion in isolated cardiomyocytes in vitro and in the heart in vivo. This further highlights the therapeutic potential of inhibiting Cx43 hemichannels and underpins the favorable outcomes obtained with other Cx-mimetic and -inhibiting peptides, Gap26 and Gap27. For instance, Gap26 administered before or after the occurrence of ischemia or as single intravenous low-dose injections protected the intact heart against ischemia-reperfusion injury (Hawat et al., 2010, 2012). Likely, therapeutic applications of L2/Gap19 peptide or like molecules are not limited to the heart, but could also be neuroprotective. For instance, Peptide 5 which is mimetic peptide that overlaps with the Gap27 domain, displayed protective effects against detrimental events following retinal ischemia/reperfusion, including a reduction in endothelial cell death, reduced vascular leakage and increased retinal ganglion cell survival in the injured retina (Danesh-Meyer et al., 2012). Inhibition of Cx43 hemichannels is also favorable to reduce inflammation by suppressing the release of inflammatory cytokines and to prevent secondary tissue damage by suppressing neuronal death after cerebral or spinal cord injuries (Huang et al., 2012; O'Carroll et al., 2008, 2013). Mechanistically, inflammatory cytokines released from microglia, like IL-1 $\beta$ and TNF- $\alpha$, increase astrocytic Cx43-hemichannel activity (Retamal et al., 2007a). The latter will be responsible for post-traumatic ATP release, which will result in neuronal death through the activation of Panx1 (Orellana et al., 2011a) and which has been implicated in aggravated secondary injury and restrained functional recovery (Huang et al., 2012). Thus, inhibition of excessive astrocytic Cx43-hemichannel activity in response to inflammatory cytokine released from microglia upon injury has neuroprotective potential (Froger et al., 2010). In particular, L2/Gap19-derived tools might be preferentially used over Gap26/Gap27 Cx-mimetic peptides, since L2/Gap19 may useful to counteract the concomitant inhibition of metabolic coupling due to gap junction inhibition observed during many of these conditions (Meme et al., 2006; Retamal et al., 2007a).

L2/Gap19 or derived molecules might also be useful in other types of injury. For instance, the cryopreservation/thawing process of arteries and veins affects the integrity of the intimal layer and the cell viability of the endothelial cells. Application of Gap27 that

Table 1

An overview of the different C-terminal Cx43 peptides. All peptides contain a common sequence that corresponds to the last 9 amino acids of the C-terminal tail of Cx43. The underlined sequence corresponds to the cell-penetrating motif that is fused to the Cx43 sequence (Antennapedia for ACT1 and TAT for TAT-CT10).

\begin{tabular}{lll}
\hline Peptide name & Peptide sequence & Developed by \\
\hline ACT1 & RQPKLWFPNRRKPWKKRPRPDDLEI & Gourdie and co-workers \\
TAT-CT10 & YGRKKRRQRRRSRPRPDLEI & Bultynck, Leybaert and co-workers \\
CT9 & RPRPDDLI & Bultynck, Leybaert and co-workers \\
\hline
\end{tabular}


targets both $\mathrm{Cx} 43$ and $\mathrm{Cx} 37$ channels during the cryopreservation/ thawing process significantly improves the conservation of the intimal layers and reduces cell death in the endothelial cells as well as smooth muscle cells. Hence, TAT-L2 (or Gap19) as a selective Cx43 inhibitor could also be used. Yet, since other Cx isoforms are expressed in the vasculature that are not targeted by TAT-L2 (or Gap19), like Cx37, the use of TAT-L2 (or Gap19) as a single agent would likely be insufficient.

Moreover, the application of these peptide tools may not be limited to counteract damage or injury by ischemia/reperfusion, but may also be relevant for neurodegenerative diseases, like Alzheimer's disease. Amyloid $\beta$ not only potentiates the action of inflammatory cytokines released from microglia on astrocytic $\mathrm{Cx} 43$ hemichannels (Meme et al., 2006), but may also increase the presence of $\mathrm{Cx} 43$ on the cell surface (Mei et al., 2010). Amyloid $\beta$ has been proposed to trigger a "toxic" signaling cascade that is driven by hemichannel activation in glial and neuronal cells. Thus, inflammatory cytokines from microglia may promote the release of glutamate and ATP through glial (microglia and astrocytes) hemichannels, thereby triggering the deleterious opening of neuronal hemichannels and resulting in neuronal cell death. Thus, L2/Gap19 or derived peptides may provide unprecedented avenues to prevent the toxic $\mathrm{Cx} 43$-hemichannel activity in glial cells, thereby promoting the survival of neuronal cells in the presence of $A \beta$ (Orellana et al., 2011b).

Finally, beyond neurodegenerative diseases, L2/Gap19 or derived molecules might be applicable to interfere with the essential role of Cx43 hemichannels in the release of gliotransmitters during fear memory consolidation (Stehberg et al., 2012). As such, tools that selectively inhibit $\mathrm{Cx} 43$ hemichannels may provide a novel strategy for the future treatment of psychiatric disorders, including anxiety and post-traumatic stress disorders.

\subsection{Concerns associated with the use of peptides targeting Cx43} hemichannels

While these peptide tools are particularly useful in biological research, it is important to note that there are a number of limitations associated to their use.

\subsubsection{Stability}

As for all peptides composed of natural amino acids, it is important to realize that these peptides might be unstable and/or degraded upon prolonged cellular incubations, thereby losing their activity. Yet, it seems that these peptide sequences remain quite stable at least for hours (Ponsaerts et al., 2010). For instance, prolonged incubation of Gap19 for 24-48 h in Cx43-expressing C6glioma cells promoted dye coupling using FRAP experiments, while completely blocking ATP release in response to moderate intracellular $\left[\mathrm{Ca}^{2+}\right]$ rises (Wang et al., 2013b). Regarding potential clinical uses, the peptides are likely to be degraded rapidly, limiting their usability to only short and localized therapeutic applications. Additionally, the peptides are expected to nonspecifically bind plasma components when administered via the I.V. route.

\subsubsection{Selectivity}

Another concern is the selectivity of these Cx43-hemichannelmodulating peptides towards other $\mathrm{Cx}$ and/or Panx isoforms. While a complete profile of the effect of these peptides on other $C x$ and Panx isoforms has not been performed, it is important to consider that the sequences corresponding to the L2 (and Gap19) region and the CT10 region are hyper variable sequences with very low homology between the different $\mathrm{Cx}$ and Panx isoforms. This is also evident from Table 2, which provides an overview of the results obtained from a BLAST search using the human Cx43 sequence.
Even Cx isoforms closely related to Cx43 (like Cx37, Cx46, Cx40, Cx50 and Cx62) display a very high heterogeneity in their "L2 sequence", while some resemblance of the "CT10" sequence of Cx43 could only be found in Cx46 and Cx40. Thus, from this analysis, it is very unlikely that TAT-L2 and Gap19, which target the CT10 region in Cx43, will affect other Cx-based hemichannels, although this ought to be scrutinized for Cx46- and Cx40-based hemichannels. Yet, our recent experiments indicate a critical role for the two Pro residues in the CT10 region of $\mathrm{CX} 43$ to establish interactions with the intracellular loop region and these Pro residues do not seem to be present in the CT10 region of Cx46 and Cx40 (D'hondt et al., 2013). Also the TAT-CT10 peptides likely display a high selectivity towards $\mathrm{Cx} 43$ hemichannels, given the very low resemblance of the L2/Gap19 region between Cx43 and other Cx isoforms. Not only sequence analysis seems to hint toward Cx43-selective tools, but also experimental analysis supports this claim. For instance, Gap19, in contrast to the established Panx1-inhibitory peptide ${ }^{10} \mathrm{Panx} 1$, did not inhibit Panx1-mediated ATP release from C6-glioma cells ectopically expressing Panx1 in response to high extracellular $\left[\mathrm{K}^{+}\right]$ (Wang et al., 2013b). Gap19 also did not affect Cx40-hemichannelmediated ATP release in response to elevated intracellular $\left[\mathrm{Ca}^{2+}\right]$ (Wang et al., 2013b). On the other hand, we found that a peptide corresponding to the sequence of the $\mathrm{L} 2$ region in $\mathrm{Cx} 50$ did not affect $\mathrm{Cx} 43$-hemichannel-driven intercellular $\mathrm{Ca}^{2+}$-wave propagation (Ponsaerts et al., 2010).

\subsubsection{Incomplete inhibition}

At the electrophysiological level, the unitary currents provoked by $\mathrm{Cx} 43$ hemichannels in Hela-Cx43 cells or ventricular cardiomyocytes were severely reduced by Gap19 incubation but were not completely inhibited, even not at high concentrations (Wang et al., 2013b). This is in contrast with the experiments that assess Cx43-hemichannel function by measuring ATP release, intercellular $\mathrm{Ca}^{2+}$ wave propagation and dye uptake, showing that Gap19 (and L2 peptide) impose a complete inhibition of these responses

Table 2

BLAST results obtained by searching database UniProtKB/SwissProt(swissprot) using PSI-BLAST (Position-Specific Iterated BLAST) by entering the human $\mathrm{Cx} 43$ sequence and limiting the output to human sequences (Altschul et al., 1997). The table only shows the regions corresponding to the L2 (Gap19 sequence is underlined) and CT10 region of human Cx43.

\begin{tabular}{|l|l|}
\hline \multicolumn{2}{|l|}{ L2 region of closely related Cx isoforms } \\
\hline Cx43 & DGVNVDMHLKQIEIKKFKYGIEEHGK \\
\hline Cx37 & KDPQVERALAAIERQMAKISVAEDGR \\
\hline Cx46 & SPSPKEPPQDNPSSR-----DDRGR \\
\hline Cx50 & SGTNGGP--DQGSVKK-SSGSKGTKK \\
\hline Cx40 & ENPDLDLEEQQRELRRLEEQKRIH-K \\
\hline Cx62 & \\
\hline RTID \\
\hline Cx43 & \\
\hline Cx37 & SRPRPDDLEI \\
\hline Cx46 & \\
\hline Cx50 & SRARPEDLAI \\
\hline Cx40 & \\
\hline Cx62 & \\
\hline
\end{tabular}


(Ponsaerts et al., 2010; Wang et al., 2013b). Thus, the passage of large signaling molecules (like ATP, which has a molecular weight of $507 \mathrm{Da}$ ) may be more affected by these peptide tools than ions. This is in line with previous observations, showing that PKCdependent phosphorylation of $\mathrm{Cx} 43$ hemichannels restricts the passage of sucrose (molecular weight of $342 \mathrm{Da}$ ) but not that of ethyleneglycol (molecular weight of 62) (Bao et al., 2007). Alternatively, the inhibition of ATP release by Gap19 and L2 might reflect a non-linear event, since a 50\% reduction of the Cx43 levels is sufficient to completely prevent ATP release (De Vuyst et al., 2009).

\subsubsection{High concentrations}

The TAT-L2, Gap19 and TAT-CT10/CT9 peptide tools require relatively high concentrations to induce their effects on $\mathrm{Cx} 43$ hemichannels. In most of our experiments, $100 \mu \mathrm{M}$ of TAT-L2 or TAT-CT10/CT9 was needed to achieve complete effects (Ponsaerts et al., 2010). TAT-L2 inhibited Cx43-hemichannel-mediated ATP release with an IC50 of about $11 \mu \mathrm{M}$, while TAT-CT10 restored $\mathrm{Cx} 43^{\mathrm{M} 239}$-hemichannel-mediated ATP release with an EC50 of about $10 \mu \mathrm{M}$ (Ponsaerts et al., 2010). This likely reflects four aspects: i) the efficiency of cell-entry of these tools; ii) the distribution of these peptides inside the cells with likely a major part of these peptides accumulating in sites/compartments devoid of $\mathrm{Cx} 43$ hemichannels; iii) the binding of these peptides to the distinct $\mathrm{Cx} 43$ regions; and iv) the low intrinsic affinity of intramolecular loop/tail interactions. In in vitro experiments, EC50 values of about $3 \mu \mathrm{M}$ were obtained for the binding of the C-terminal tail of $\mathrm{Cx} 43$ to biotin-L2 and biotin-Gap19 (Wang et al., 2013b). Thus, the relatively high IC50 values (about $50 \mu \mathrm{M}$ ) obtained for native Gap19 to inhibit Cx43-mediated ATP release likely reflect its sub-optimal cell-entry properties (Wang et al., 2013b). Consistent with this, improving Gap19's cell-entry properties by coupling it to the TAT sequence significantly lowered this IC50 value (Wang et al., 2013a,b; see supplementary material). In any case, the use of proper control peptides like inactive mutants (TAT-L2 ${ }^{\mathrm{H} 126 \mathrm{~K} / 1130 \mathrm{~N}}$, Gap19 ${ }^{\mathrm{I130A}}$, or TAT-CT10 ${ }^{\mathrm{D} 377 \mathrm{~A} / \mathrm{D} 378 \mathrm{~A}}$ ) or scrambled/reversed sequence peptides are essential to assess non-specific effects. Further support for the increase in cell-entry properties by the use of peptide coupling with TAT sequence comes from in vivo experiments, where TAT-L2 micro-injected into the basolateral amygdala had significant amnesic effects in memory consolidation when injecting as low as $10 \mathrm{nM}$ of TAT-L2 (Stehberg et al., 2012). Although it is technically challenging to evaluate the effects of the peptide on $\mathrm{Cx} 43$ hemichannel opening in vivo, the physiological effectiveness of TAT-L2 at $10 \mathrm{nM}$, while TAT-L2 ${ }^{\mathrm{H} 126 \mathrm{~K} / 1130 \mathrm{~N}}$ was without effect, ascertains the peptide's direct actions on $\mathrm{Cx} 43$ hemichannels and rules out pleiotropic effects. Also, these data suggest that a decrease in Cx43 hemichannel activity can have important physiological effects without necessarily requiring the complete silencing of the hemichannels.

\section{Perspectives and conclusions}

Thus, it is clear that intramolecular interactions between the Cterminal tail and the cytoplasmic loop of $\mathrm{Cx} 43$ critically control the activity of gap junction channels and hemichannels but with a different outcome. In gap junctions occurs the binding of the Cterminal tail to the cytoplasmic loop during pathological conditions like acidosis, leading to the closure of gap junction channels. In contrast, in hemichannels, the binding of the C-terminal tail to the cytoplasmic loop is essential for the opening of $\mathrm{Cx} 43$ hemichannels in response to different cellular stimuli, including increases in cytosolic $\left[\mathrm{Ca}^{2+}\right]$ in the physiological range (between $100 \mathrm{nM}$ and $500 \mathrm{nM}$ ). Interestingly, the same molecular determinants underlie loop/tail binding in gap junctions and hemichannels, including at least the $\mathrm{L} 2$ region as the receptor and the CT10 region as part of the particle. As a consequence, peptides targeting these regions seem to provoke opposite effects. For instance, TAT-L2 promotes gap junction channel opening and prevents its closure during acidosis and inhibits hemichannel opening in response to cellular stimuli. This opens novel scientific and therapeutic perspectives to use TATL2 and peptide variants to selectively inhibit $\mathrm{Cx} 43$ hemichannels while maintaining Cx43 gap junction channels. Therefore, TAT-L2 and its nonapeptide variant Gap19 can be used as a selective Cx43-hemichannel inhibitor in cellular models and organs to pinpoint the contribution of $\mathrm{Cx} 43$ hemichannels in cell biological and physiological processes. In the brain and the heart, these peptides can be applied to counteract excessive hemichannel activity during ischemia/reperfusion or metabolic inhibition, while sustaining gap junction communication, essential for action potential spreading in the heart or glucose spreading within astrocyte layers. Furthermore, the recently discovered role of Cx43 hemichannels in fear memory consolidation highlights the potential of TAT-L2/Gap19 as attractive lead compounds to tackle various psychiatric and neurological disorders where excessive hemichannel function is part of the pathophysiological problem.

Nevertheless, a number of questions remain about intramolecular loop/tail interactions regulating $\mathrm{Cx} 43$ hemichannels. For instance, it is not known whether in analogy to gap junction channels other regions in the C-terminal tail besides the CT10 amino acid stretch are involved in binding to the $\mathrm{L} 2$ receptor region. It is also not clear how binding of the C-terminal tail to the cytoplasmic loop leads to opening of $\mathrm{Cx} 43$ hemichannels but closure of Cx43 gap junction channels. This likely involves differences in conformation between undocked hemichannels and head-to-headdocked gap junction channels, pointing to an important role for the extracellular loops. Moreover, it is not clear whether the C-terminal tail is always bound to the cytoplasmic loop or whether the binding is induced upon exposure to stimuli like strong depolarization, extracellular $\mathrm{Ca}^{2+}$ buffers or intracellular $\mathrm{Ca}^{2+}$-mobilizing agents. In any case, since $\mathrm{Cx} 43$ hemichannels can permeate $\mathrm{Ca}^{2+}$ and thus influence intracellular $\left[\mathrm{Ca}^{2+}\right]$ and intracellular $\left[\mathrm{Ca}^{2+}\right]$ influence Cx43-hemichannel opening, it will be critical to assess the role of intracellular $\mathrm{Ca}^{2+}$ in loop/tail interactions. $\mathrm{Ca}^{2+}$ may directly affect the conformation of the cytoplasmic loop or C-terminal tail, thereby altering their binding properties, or may indirectly affect loop/tail interactions through $\mathrm{Ca}^{2+}$-binding proteins, like calmodulin, which binds near the $\mathrm{L} 2$ region or through $\mathrm{Ca}^{2+}$-dependent phosphorylation/dephosphorylation processes. In addition, intracellular $\mathrm{Ca}^{2+}$ may also alter the ability of C-terminal tail to dimerize, an essential step in binding L2 in gap junctions. Yet, the importance of C-terminal tail dimerization for the opening Cx43 hemichannels or rendering them in an activatable state remains elusive. Finally, until know, all of our evidence has been obtained with $\mathrm{Cx} 43$ hemichannels, but it is not clear whether hemichannels formed by other $\mathrm{Cx}$ isoform too are controlled by loop/tail interactions. A likely candidate that might be controlled by loop/tail interactions is Cx32, since Cx32 hemichannels too display a bell-shaped dependence towards intracellular $\left[\mathrm{Ca}^{2+}\right]$ (De Vuyst et al., 2006).

In conclusion, loop/tail interactions in $\mathrm{Cx} 43$ involving the $\mathrm{L} 2$ and CT10 regions are an important switch that turns off $\mathrm{Cx} 43$ gap junction channels, while turning on $\mathrm{Cx} 43$ hemichannels, leading to opposite outcomes. These interactions can be exploited by Cx43mimetic peptides that target these hot spots for interactions, thereby leading to unprecedented opportunities to inhibit $\mathrm{Cx} 43$ hemichannels while maintaining $\mathrm{Cx} 43$ gap junction coupling.

\section{Acknowledgments}

The authors thank their lab members for helpful discussions. GB wants to thank Dr. Rob Gourdie for helpful discussions on the ACT1 
peptide. Work performed in the authors' laboratory was supported by research grants from the Research Foundation-Flanders (F.W.O. grant: G.0298.11 to L.L. and G.B.), Interuniversity Attraction Poles Program (Belgian Science Policy, project P7/10 to L.L., and P7/13 to G.B.), Universidad Andrés Bello (UNAB) (grant UNAB DI-02-11/N (to J.S.), and by Anillo ACT1104 and Fondecyt 1120214 (to M.A.R.). C.D.H. is supported by a post-doctoral fellowship from the Research Foundation-Flanders (F.W.O.).

\section{References}

Altschul, S.F., Madden, T.L., Schaffer, A.A., Zhang, J., Zhang, Z., Miller, W., Lipman, D.J., 1997. Gapped BLAST and PSI-BLAST: a new generation of protein database search programs. Nucleic Acids Res. 25, 3389-3402.

Ambrosi, C., Gassmann, O., Pranskevich, J.N., Boassa, D., Smock, A., Wang, J., Dahl, G., Steinem, C., Sosinsky, G.E., 2010. Pannexin1 and Pannexin2 channels show quaternary similarities to connexons and different oligomerization numbers from each other. J. Biol. Chem. 285, 24420-24431.

Axelsen, L.N., Stahlhut, M., Mohammed, S., Larsen, B.D., Nielsen, M.S., HolsteinRathlou, N.H., Andersen, S., Jensen, O.N., Hennan, J.K., Kjolbye, A.L., 2006. Identification of ischemia-regulated phosphorylation sites in connexin43: a possible target for the antiarrhythmic peptide analogue rotigaptide (ZP123). J. Mol. Cell. Cardiol. 40, 790-798.

Bao, X., Lee, S.C., Reuss, L., Altenberg, G.A., 2007. Change in permeant size selectivity by phosphorylation of connexin 43 gap-junctional hemichannels by PKC. Proc. Natl. Acad. Sci. U.S.A. 104, 4919-4924.

Bezprozvanny, I., Watras, J., Ehrlich, B.E., 1991. Bell-shaped calcium-response curves of Ins(1,4,5)P3- and calcium-gated channels from endoplasmic reticulum of cerebellum. Nature 351, 751-754.

Billaud, M., Sandilos, J.K., Isakson, B.E., 2012. Pannexin 1 in the regulation of vascular tone. Trends Cardiovasc. Med. 22, 68-72.

Bukauskas, F.F., Jordan, K., Bukauskiene, A., Bennett, M.V., Lampe, P.D., Laird, D.W., Verselis, V.K., 2000. Clustering of connexin 43-enhanced green fluorescent protein gap junction channels and functional coupling in living cells. Proc. Natl. Acad. Sci. U.S.A. 97, 2556-2561.

Calero, G., Kanemitsu, M., Taffet, S.M., Lau, A.F., Delmar, M., 1998. A 17mer peptide interferes with acidification-induced uncoupling of connexin43. Circ. Res. 82, 929-935.

Chandrasekhar, A., Bera, A.K., 2012. Hemichannels: permeants and their effect on development, physiology and death. Cell Biochem. Funct. 30, 89-100.

Contreras, J.E., Saez, J.C., Bukauskas, F.F., Bennett, M.V., 2003. Gating and regulation of connexin 43 (Cx43) hemichannels. Proc. Natl. Acad. Sci. U.S.A. 100, 1138811393.

D'hondt, C. Iyyathurai, J., Wang, N., Gourdie, R.G., Himpens, B., Leybaert, L., Bultynck, G., 2013. Negatively charged residues (Asp378 and Asp379) in the last ten amino acids of the C-terminal tail of Cx43 hemichannels are essential for loop/tail interactions. Biochem. Biophys. Res. Commun. 432, 707-712.

D'hondt, C., Ponsaerts, R., De Smedt, H., Bultynck, G., Himpens, B., 2009. Pannexins, distant relatives of the connexin family with specific cellular functions? Bioessays 31, 953-974.

D'hondt, C., Ponsaerts, R., De Smedt, H., Vinken, M., De Vuyst, E., De Bock, M., Wang, N., Rogiers, V., Leybaert, L., Himpens, B., Bultynck, G., 2011. Pannexin channels in ATP release and beyond: an unexpected rendezvous at the endoplasmic reticulum. Cell. Signal. 23, 305-316.

Danesh-Meyer, H.V., Kerr, N.M., Zhang, J., Eady, E.K., O’Carroll, S.J., Nicholson, L.F., Johnson, C.S., Green, C.R., 2012. Connexin43 mimetic peptide reduces vascular leak and retinal ganglion cell death following retinal ischaemia. Brain 135, 506520.

De Bock, M., Culot, M., Wang, N., Bol, M., Decrock, E., De Vuyst, E., da Costa, A., Dauwe, I., Vinken, M., Simon, A.M., Rogiers, V., De Ley, G., Evans, W.H., Bultynck, G., Dupont, G., Cecchelli, R., Leybaert, L., 2011. Connexin channels provide a target to manipulate brain endothelial calcium dynamics and bloodbrain barrier permeability. J. Cereb. Blood Flow Metab. 31, 1942-1957.

De Bock, M., Wang, N., Bol, M., Decrock, E., Ponsaerts, R., Bultynck, G., Dupont, G., Leybaert, L., 2012. Connexin 43 hemichannels contribute to cytoplasmic Ca2+ oscillations by providing a bimodal $\mathrm{Ca} 2+$-dependent $\mathrm{Ca} 2+$ entry pathway. J. Biol. Chem. 287, 12250-12266.

De Vuyst, E., Boengler, K., Antoons, G., Sipido, K.R., Schulz, R., Leybaert, L., 2011 Pharmacological modulation of connexin-formed channels in cardiac pathophysiology. Br. J. Pharmacol. 163, 469-483.

De Vuyst, E., De Bock, M., Decrock, E., Van Moorhem, M., Naus, C., Mabilde, C., Leybaert, L., 2008. In situ bipolar electroporation for localized cell loading with reporter dyes and investigating gap junctional coupling. Biophys. J. 94, 469-479.

De Vuyst, E., Decrock, E., Cabooter, L., Dubyak, G.R., Naus, C.C., Evans, W.H., Leybaert, L., 2006. Intracellular calcium changes trigger connexin 32 hemichannel opening. EMBO J. 25, 34-44.

De Vuyst, E., Decrock, E., De Bock, M., Yamasaki, H., Naus, C.C., Evans, W.H. Leybaert, L., 2007. Connexin hemichannels and gap junction channels are differentially influenced by lipopolysaccharide and basic fibroblast growth factor. Mol. Biol. Cell. 18, 34-46.
De Vuyst, E., Wang, N., Decrock, E., De Bock, M., Vinken, M., Van Moorhem, M., Lai, C., Culot, M., Rogiers, V., Cecchelli, R., Naus, C.C., Evans, W.H., Leybaert, L., 2009. $\mathrm{Ca}(2+)$ regulation of connexin 43 hemichannels in $\mathrm{C} 6$ glioma and glial cells. Cell Calcium 46, 176-187.

Decrock, E., De Bock, M., Wang, N., Gadicherla, A.K., Bol, M., Delvaeye, T., Vandenabeele, P., Vinken, M., Bultynck, G., Krysko, D.V., Leybaert, L., 2013. IP(3), a small molecule with a powerful message. Biochim. Biophys. Acta.

Decrock, E., De Vuyst, E., Vinken, M., Van Moorhem, M., Vranckx, K., Wang, N., Van Laeken, L., De Bock, M., D'Herde, K., Lai, C.P., Rogiers, V., Evans, W.H., Naus, C.C., Leybaert, L., 2009a. Connexin 43 hemichannels contribute to the propagation of apoptotic cell death in a rat C6 glioma cell model. Cell Death Differ. 16, 151-163.

Decrock, E., Krysko, D.V., Vinken, M., Kaczmarek, A., Crispino, G., Bol, M., Wang, N., De Bock, M., De Vuyst, E., Naus, C.C., Rogiers, V., Vandenabeele, P., Erneux, C., Mammano, F., Bultynck, G., Leybaert, L., 2012. Transfer of IP(3) through gap junctions is critical, but not sufficient, for the spread of apoptosis. Cell Death Differ. 19, 947-957.

Decrock, E., Vinken, M., Bol, M., D'Herde, K., Rogiers, V., Vandenabeele, P., Krysko, D.V., Bultynck, G., Leybaert, L., 2011. Calcium and connexin-based intercellular communication, a deadly catch? Cell Calcium 50, 310-321.

Decrock, E., Vinken, M., De Vuyst, E., Krysko, D.V., D’Herde, K., Vanhaecke, T., Vandenabeele, P., Rogiers, V., Leybaert, L., 2009b. Connexin-related signaling in cell death: to live or let die? Cell Death Differ. 16, 524-536.

Delmar, M., Makita, N., 2012. Cardiac connexins, mutations and arrhythmias. Curr. Opin. Cardiol. 27, 236-241.

Dhein, S., Larsen, B.D., Petersen, J.S., Mohr, F.W., 2003. Effects of the new antiarrhythmic peptide ZP123 on epicardial activation and repolarization pattern. Cell Commun. Adhes. 10, 371-378.

Dhein, S., Manicone, N., Muller, A., Gerwin, R., Ziskoven, U., Irankhahi, A., Minke, C., Klaus, W., 1994. A new synthetic antiarrhythmic peptide reduces dispersion of epicardial activation recovery interval and diminishes alterations of epicardial activation patterns induced by regional ischemia. A mapping study. Naunyn Schmiedebergs Arch. Pharmacol. 350, 174-184.

Dobrowolski, R., Sommershof, A., Willecke, K., 2007. Some oculodentodigital dysplasia-associated Cx43 mutations cause increased hemichannel activity in addition to deficient gap junction channels. J. Membr. Biol. 219, 9-17.

Duffy, H.S., Ashton, A.W., O’Donnell, P., Coombs, W., Taffet, S.M., Delmar, M., Spray, D.C., 2004. Regulation of connexin43 protein complexes by intracellular acidification. Circ. Res. 94, 215-222.

Duffy, H.S., Sorgen, P.L., Girvin, M.E., O'Donnell, P., Coombs, W., Taffet, S.M., Delmar, M., Spray, D.C., 2002. pH-dependent intramolecular binding and structure involving Cx43 cytoplasmic domains. J. Biol. Chem. 277, 3670636714 .

Easton, J.A., Petersen, J.S., Martin, P.E., 2009. The anti-arrhythmic peptide AAP10 remodels Cx43 and Cx40 expression and function. Naunyn Schmiedebergs Arch. Pharmacol. 380, 11-24.

Ek-Vitorin, J.F., Calero, G., Morley, G.E., Coombs, W., Taffet, S.M., Delmar, M., 1996. PH regulation of connexin43: molecular analysis of the gating particle. Biophys. J. $71,1273-1284$

Ek-Vitorin, J.F., King, T.J., Heyman, N.S., Lampe, P.D., Burt, J.M., 2006. Selectivity of connexin 43 channels is regulated through protein kinase C-dependent phosphorylation. Circ. Res. 98, 1498-1505.

Ek, J.F., Delmar, M., Perzova, R., Taffet, S.M., 1994. Role of histidine 95 on pH gating of the cardiac gap junction protein connexin43. Circ. Res. 74, 1058-1064.

Eloff, B.C., Gilat, E., Wan, X., Rosenbaum, D.S., 2003. Pharmacological modulation of cardiac gap junctions to enhance cardiac conduction: evidence supporting a novel target for antiarrhythmic therapy. Circulation 108, 3157-3163.

Evans, W.H., Bultynck, G., Leybaert, L., 2012. Manipulating connexin communication channels: use of peptidomimetics and the translational outputs. J. Membr. Biol. 245, 437-449.

Evans, W.H., De Vuyst, E., Leybaert, L., 2006. The gap junction cellular internet: connexin hemichannels enter the signalling limelight. Biochem. J. 397, 1-14.

Fellin, T., Sul, J.Y., D’Ascenzo, M., Takano, H., Pascual, O., Haydon, P.G., 2006. Bidirectional astrocyte-neuron communication: the many roles of glutamate and ATP. Novartis Found Symp. 276, 208-217 (discussion 217-221, 233-207, 275281).

Froger, N., Orellana, J.A., Calvo, C.F., Amigou, E., Kozoriz, M.G., Naus, C.C., Saez, J.C., Giaume, C., 2010. Inhibition of cytokine-induced connexin43 hemichannel activity in astrocytes is neuroprotective. Mol. Cell. Neurosci. 45, 37-46.

Garre, J.M., Retamal, M.A., Cassina, P., Barbeito, L., Bukauskas, F.F., Saez, J.C., Bennett, M.V., Abudara, V., 2010. FGF-1 induces ATP release from spinal astrocytes in culture and opens pannexin and connexin hemichannels. Proc. Natl. Acad. Sci. U.S.A. 107, 22659-22664.

Ghatnekar, G.S., O'Quinn, M.P., Jourdan, L.J., Gurjarpadhye, A.A., Draughn, R.L., Gourdie, R.G., 2009. Connexin43 carboxyl-terminal peptides reduce scar progenitor and promote regenerative healing following skin wounding. Regen. Med. 4, 205-223.

Giepmans, B.N., Hengeveld, T., Postma, F.R., Moolenaar, W.H., 2001. Interaction of cSrc with gap junction protein connexin-43. Role in the regulation of cell-cell communication. J. Biol. Chem. 276, 8544-8549.

Giepmans, B.N., Moolenaar, W.H., 1998. The gap junction protein connexin43 interacts with the second PDZ domain of the zona occludens-1 protein. Curr. Biol. 8, 931-934.

Gourdie, R.G., Ghatnekar, G.S., O'Quinn, M., Rhett, M.J., Barker, R.J., Zhu, C., Jourdan, J., Hunter, A.W., 2006. The unstoppable connexin43 carboxyl- 
terminus: new roles in gap junction organization and wound healing. Ann. N.Y. Acad. Sci. 1080, 49-62.

Grover, R., Dhein, S., 2001. Structure-activity relationships of novel peptides related to the antiarrhythmic peptide AAP10 which reduce the dispersion of epicardial action potential duration. Peptides 22, 1011-1021.

Gu, H., Ek-Vitorin, J.F., Taffet, S.M., Delmar, M., 2000. Coexpression of connexins 40 and 43 enhances the pH sensitivity of gap junctions: a model for synergistic interactions among connexins. Circ. Res. 86, E98-E103.

Guerra, J.M., Everett, T.H.t., Lee, K.W., Wilson, E., Olgin, J.E., 2006. Effects of the gap junction modifier rotigaptide (ZP123) on atrial conduction and vulnerability to atrial fibrillation. Circulation 114, 110-118.

Hagen, A., Dietze, A., Dhein, S., 2009. Human cardiac gap-junction coupling: effects of antiarrhythmic peptide AAP10. Cardiovasc. Res. 83, 405-415.

Haugan, K., Marcussen, N., Kjolbye, A.L., Nielsen, M.S., Hennan, J.K., Petersen, J.S. 2006. Treatment with the gap junction modifier rotigaptide (ZP123) reduces infarct size in rats with chronic myocardial infarction. J. Cardiovasc. Pharmacol. $47,236-242$.

Haugan, K., Olsen, K.B., Hartvig, L., Petersen, J.S., Holstein-Rathlou, N.H., Hennan, J.K., Nielsen, M.S., 2005. The antiarrhythmic peptide analog ZP123 prevents atrial conduction slowing during metabolic stress. J. Cardiovasc. Electrophysiol. 16, 537-545.

Hawat, G., Benderdour, M., Rousseau, G., Baroudi, G., 2010. Connexin 43 mimetic peptide Gap26 confers protection to intact heart against myocardial ischemia injury. Pflugers Arch. 460, 583-592.

Hawat, G., Helie, P., Baroudi, G., 2012. Single intravenous low-dose injections of connexin 43 mimetic peptides protect ischemic heart in vivo against myocardial infarction. J. Mol. Cell. Cardiol. 53, 559-566.

Hennan, J.K., Swillo, R.E., Morgan, G.A., Keith Jr., J.C., Schaub, R.G., Smith, R.P., Feldman, H.S., Haugan, K., Kantrowitz, J., Wang, P.J., Abu-Qare, A., Butera, J., Larsen, B.D., Crandall, D.L., 2006. Rotigaptide (ZP123) prevents spontaneous ventricular arrhythmias and reduces infarct size during myocardial ischemia/ reperfusion injury in open-chest dogs. J. Pharmacol. Exp. Ther. 317, 236-243.

Herve, J.C., Bourmeyster, N., Sarrouilhe, D., Duffy, H.S., 2007. Gap junctional complexes: from partners to functions. Prog. Biophys. Mol. Biol. 94, 29-65.

Herve, J.C., Derangeon, M., 2012. Gap-junction-mediated cell-to-cell communication. Cell. Tissue Res.

Herve, J.C., Dhein, S., 2006. Pharmacology of cardiovascular gap junctions. Adv. Cardiol. 42, 107-131.

Herve, J.C., Dhein, S., 2010. Peptides targeting gap junctional structures. Curr. Pharm. Des. 16, 3056-3070.

Hirst-Jensen, B.J., Sahoo, P., Kieken, F., Delmar, M., Sorgen, P.L., 2007. Characterization of the $\mathrm{pH}$-dependent interaction between the gap junction protein connexin 43 carboxyl terminus and cytoplasmic loop domains. J. Biol. Chem. 282, 5801-5813.

Homma, N., Alvarado, J.L., Coombs, W., Stergiopoulos, K., Taffet, S.M., Lau, A.F. Delmar, M., 1998. A particle-receptor model for the insulin-induced closure of connexin43 channels. Circ. Res. 83, 27-32.

Huang, C., Han, X., Li, X., Lam, E., Peng, W., Lou, N., Torres, A., Yang, M., Garre, J.M. Tian, G.F., Bennett, M.V., Nedergaard, M., Takano, T., 2012. Critical role of connexin 43 in secondary expansion of traumatic spinal cord injury. J. Neurosci. 32 $3333-3338$

Hunter, A.W., Barker, R.J., Zhu, C., Gourdie, R.G., 2005. Zonula occludens-1 alters connexin43 gap junction size and organization by influencing channel accretion. Mol. Biol. Cell 16, 5686-5698.

Hunter, A.W., Gourdie, R.G., 2008. The second PDZ domain of zonula occludens-1 is dispensable for targeting to connexin 43 gap junctions. Cell Commun. Adhes. $15,55-63$.

Hunter, A.W., Jourdan, J., Gourdie, R.G., 2003. Fusion of GFP to the carboxyl terminus of connexin43 increases gap junction size in HeLa cells. Cell Commun. Adhes. $10,211-214$.

Iino, M., 1990. Biphasic Ca2+ dependence of inositol 1,4,5-trisphosphate-induced Ca release in smooth muscle cells of the guinea pig taenia caeci. J. Gen. Physiol. 95 $1103-1122$.

Ishikawa, M., Iwamoto, T., Nakamura, T., Doyle, A., Fukumoto, S., Yamada, Y., 2011. Pannexin 3 functions as an ER $\mathrm{Ca}(2+)$ channel, hemichannel, and gap junction to promote osteoblast differentiation. J. Cell Biol. 193, 1257-1274.

Johansen, D., Cruciani, V., Sundset, R., Ytrehus, K., Mikalsen, S.O., 2011. Ischemia induces closure of gap junctional channels and opening of hemichannels in heart-derived cells and tissue. Cell. Physiol. Biochem. 28, 103-114.

John, S.A., Kondo, R., Wang, S.Y., Goldhaber, J.I., Weiss, J.N., 1999. Connexin-43 hemichannels opened by metabolic inhibition. J. Biol. Chem. 274, 236-240.

Johnstone, S.R., Billaud, M., Lohman, A.W., Taddeo, E.P., Isakson, B.E., 2012. Posttranslational modifications in connexins and pannexins. J. Membr. Biol. 245, 319-332.

Jozwiak, J., Dhein, S., 2008. Local effects and mechanisms of antiarrhythmic peptide AAP10 in acute regional myocardial ischemia: electrophysiological and molecular findings. Naunyn Schmiedebergs Arch. Pharmacol. 378, 459-470.

Kanemitsu, M.Y., Loo, L.W., Simon, S., Lau, A.F., Eckhart, W., 1997. Tyrosine phosphorylation of connexin 43 by v-Src is mediated by $\mathrm{SH} 2$ and $\mathrm{SH} 3$ domain interactions. J. Biol. Chem. 272, 22824-22831.

Kang, J., Kang, N., Lovatt, D., Torres, A., Zhao, Z., Lin, J., Nedergaard, M., 2008 Connexin 43 hemichannels are permeable to ATP. J. Neurosci. 28, 4702-4711.

Kar, R., Batra, N., Riquelme, M.A., Jiang, J.X., 2012. Biological role of connexin intercellular channels and hemichannels. Arch. Biochem. Biophys. 524, 2-15.

Kettenmann, H., Hanisch, U.K., Noda, M., Verkhratsky, A., 2011. Physiology of microglia. Physiol. Rev. 91, 461-553.
Kondo, R.P., Wang, S.Y., John, S.A., Weiss, J.N., Goldhaber, J.I., 2000. Metabolic inhibition activates a non-selective current through connexin hemichannels in isolated ventricular myocytes. J. Mol. Cell. Cardiol. 32, 1859-1872.

Lampe, P.D., Lau, A.F., 2000. Regulation of gap junctions by phosphorylation of connexins. Arch. Biochem. Biophys. 384, 205-215.

Lewandowski, R., Procida, K., Vaidyanathan, R., Coombs, W., Jalife, J., Nielsen, M.S. Taffet, S.M., Delmar, M., 2008. RXP-E: a connexin43-binding peptide that prevents action potential propagation block. Circ. Res. 103, 519-526.

Leybaert, L., Sanderson, M.J., 2012. Intercellular $\mathrm{Ca}(2+)$ waves: mechanisms and function. Physiol. Rev. 92, 1359-1392.

Li, F., Sugishita, K., Su, Z., Ueda, I., Barry, W.H., 2001. Activation of connexin-43 hemichannels can elevate $[\mathrm{Ca}(2+)] \mathrm{i}$ and $[\mathrm{Na}(+)] \mathrm{i}$ in rabbit ventricular myocytes during metabolic inhibition. J. Mol. Cell. Cardiol. 33, 2145-2155.

Liu, S., Taffet, S., Stoner, L., Delmar, M., Vallano, M.L., Jalife, J., 1993. A structural basis or the unequal sensitivity of the major cardiac and liver gap junctions to intracellular acidification: the carboxyl tail length. Biophys. J. 64, 1422-1433.

Loiselle, A.E., Jiang, J.X., Donahue, H.J., 2012. Gap junction and hemichannel functions in osteocytes. Bone.

Maass, K., Shibayama, J., Chase, S.E., Willecke, K., Delmar, M., 2007. C-terminal truncation of connexin43 changes number, size, and localization of cardiac gap junction plaques. Circ. Res. 101, 1283-1291.

Macia, E., Dolmatova, E., Cabo, C., Sosinsky, A.Z., Dun, W., Coromilas, J., Ciaccio, E.J., Boyden, P.A., Wit, A.L., Duffy, H.S., 2011. Characterization of gap junction remodeling in epicardial border zone of healing canine infarcts and electrophysiological effects of partial reversal by rotigaptide. Circ. Arrhythm Electrophysiol. 4, 344-351.

Mei, X., Ezan, P., Giaume, C., Koulakoff, A., 2010. Astroglial connexin immunoreactivity is specifically altered at beta-amyloid plaques in beta-amyloid precursor protein/presenilin1 mice. Neuroscience 171, 92-105.

Meme, W., Calvo, C.F., Froger, N., Ezan, P., Amigou, E., Koulakoff, A., Giaume, C., 2006 Proinflammatory cytokines released from microglia inhibit gap junctions in astrocytes: potentiation by beta-amyloid. FASEB J. 20, 494-496.

Miro-Casas, E., Ruiz-Meana, M., Agullo, E., Stahlhofen, S., Rodriguez-Sinovas, A. Cabestrero, A., Jorge, I., Torre, I., Vazquez, J., Boengler, K., Schulz, R., Heusch, G. Garcia-Dorado, D., 2009. Connexin43 in cardiomyocyte mitochondria contributes to mitochondrial potassium uptake. Cardiovasc. Res. 83, 747-756.

Morley, G.E., Taffet, S.M., Delmar, M., 1996. Intramolecular interactions mediate pH regulation of connexin43 channels. Biophys. J. 70, 1294-1302.

O'Carroll, S.J., Alkadhi, M., Nicholson, L.F., Green, C.R., 2008. Connexin 43 mimetic peptides reduce swelling, astrogliosis, and neuronal cell death after spinal cord injury. Cell Commun. Adhes. 15, 27-42.

O'Carroll, S.J., Gorrie, C.A., Velamoor, S., Green, C.R., Nicholson, L.F., 2013. Connexin43 mimetic peptide is neuroprotective and improves function following spinal cord injury. Neurosci. Res. 75, 256-267.

O'Quinn, M.P., Palatinus, J.A., Harris, B.S., Hewett, K.W., Gourdie, R.G., 2011. A peptide mimetic of the connexin43 carboxyl terminus reduces gap junction remodeling and induced arrhythmia following ventricular injury. Circ. Res. 108 , 704-715.

Orellana, J.A., Froger, N., Ezan, P., Jiang, J.X., Bennett, M.V., Naus, C.C., Giaume, C. Saez, J.C., 2011a. ATP and glutamate released via astroglial connexin 43 hemichannels mediate neuronal death through activation of pannexin 1 hemichannels. J. Neurochem. 118, 826-840.

Orellana, J.A., Shoji, K.F., Abudara, V., Ezan, P., Amigou, E., Saez, P.J., Jiang, J.X. Naus, C.C., Saez, J.C. Giaume, C., 2011b. Amyloid beta-induced death in neurons involves glial and neuronal hemichannels. J. Neurosci. 31, 4962-4977.

Palatinus, J.A., O'Quinn, M.P., Barker, R.J., Harris, B.S., Jourdan, J., Gourdie, R.G., 2011a. $\mathrm{ZO}-1$ determines adherens and gap junction localization at intercalated disks. Am. J. Physiol. Heart Circ. Physiol. 300, H583-H594.

Palatinus, J.A., Rhett, J.M., Gourdie, R.G., 2011b. Enhanced PKCepsilon mediated phosphorylation of connexin 43 at serine 368 by a carboxyl-terminal mimetic peptide is dependent on injury. Channels (Austin) 5, 236-240.

Palatinus, J.A., Rhett, J.M., Gourdie, R.G., 2012. The connexin43 carboxyl terminus and cardiac gap junction organization. Biochim. Biophys. Acta 1818, 18311843.

Paul, D.L., Ebihara, L., Takemoto, L.J., Swenson, K.I., Goodenough, D.A., 1991. Connexin46, a novel lens gap junction protein, induces voltage-gated currents in nonjunctional plasma membrane of Xenopus oocytes. J. Cell Biol. 115, 10771089.

Ponsaerts, R., D’hondt, C., Bultynck, G., Srinivas, S.P., Vereecke, J., Himpens, B., 2008 The myosin II ATPase inhibitor blebbistatin prevents thrombin-induced inhibition of intercellular calcium wave propagation in corneal endothelial cells. Invest. Ophthalmol. Vis. Sci. 49, 4816-4827.

Ponsaerts, R., D'Hondt, C., Hertens, F., Parys, J.B., Leybaert, L., Vereecke, J., Himpens, B., Bultynck, G., 2012a. RhoA GTPase switch controls Cx43hemichannel activity through the contractile system. PLoS One 7, e42074.

Ponsaerts, R., De Vuyst, E., Retamal, M., D’hondt, C., Vermeire, D., Wang, N., De Smedt, H., Zimmermann, P., Himpens, B., Vereecke, J., Leybaert, L., Bultynck, G., 2010. Intramolecular loop/tail interactions are essential for connexin 43hemichannel activity. FASEB J. 24, 4378-4395.

Ponsaerts, R., Wang, N., Himpens, B., Leybaert, L., Bultynck, G., 2012b. The contractile system as a negative regulator of the connexin 43 hemichannel. Biol. Cell 104, 367-377.

Postma, F.R., Hengeveld, T., Alblas, J., Giepmans, B.N., Zondag, G.C., Jalink, K. Moolenaar, W.H., 1998. Acute loss of cell-cell communication caused by C protein-coupled receptors: a critical role for c-Src. J. Cell Biol. 140, 1199-1209. 
Retamal, M.A., Cortes, C.J., Reuss, L., Bennett, M.V., Saez, J.C., 2006. S-nitrosylation and permeation through connexin 43 hemichannels in astrocytes: induction by oxidant stress and reversal by reducing agents. Proc. Natl. Acad. Sci. U.S.A. 103, $4475-4480$.

Retamal, M.A., Froger, N., Palacios-Prado, N., Ezan, P., Saez, P.J., Saez, J.C., Giaume, C., 2007a. Cx43 hemichannels and gap junction channels in astrocytes are regulated oppositely by proinflammatory cytokines released from activated microglia. J. Neurosci. 27, 13781-13792.

Retamal, M.A., Schalper, K.A., Shoji, K.F., Bennett, M.V., Saez, J.C., 2007b. Opening of connexin 43 hemichannels is increased by lowering intracellular redox potential. Proc. Natl. Acad. Sci. U.S.A. 104, 8322-8327.

Retamal, M.A., Schalper, K.A., Shoji, K.F., Orellana, J.A., Bennett, M.V., Saez, J.C., 2007c. Possible involvement of different connexin 43 domains in plasma membrane permeabilization induced by ischemia-reperfusion. J. Membr. Biol. $218,49-63$.

Rhett, J.M., Ghatnekar, G.S., Palatinus, J.A., O'Quinn, M., Yost, M.J., Gourdie, R.G., 2008. Novel therapies for scar reduction and regenerative healing of skin wounds. Trends Biotechnol. 26, 173-180.

Rhett, J.M., Gourdie, R.G., 2012. The perinexus: a new feature of $\mathrm{Cx} 43$ gap junction organization. Heart Rhythm 9, 619-623.

Rhett, J.M., Jourdan, J., Gourdie, R.G., 2011. Connexin 43 connexon to gap junction transition is regulated by zonula occludens-1. Mol. Biol. Cell 22, 1516-1528.

Saez, J.C., Berthoud, V.M., Branes, M.C., Martinez, A.D., Beyer, E.C., 2003. Plasma membrane channels formed by connexins: their regulation and functions. Physiol. Rev. 83, 1359-1400.

Santello, M., Cali, C., Bezzi, P., 2012. Gliotransmission and the tripartite synapse. Adv. Exp. Med. Biol. 970, 307-331.

Scemes, E., 2012. Nature of plasmalemmal functional "hemichannels". Biochim. Biophys. Acta $1818,1880-1883$.

Scemes, E., Spray, D.C., Meda, P., 2009. Connexins, pannexins, innexins: novel roles of "hemi-channels". Pflugers Arch. 457, 1207-1226.

Scemes, E., Suadicani, S.O., Dahl, G., Spray, D.C., 2007. Connexin and pannexin mediated cell-cell communication. Neuron Glia Biol. 3, 199-208.

Schalper, K.A., Palacios-Prado, N., Retamal, M.A., Shoji, K.F., Martinez, A.D., Saez, J.C., 2008. Connexin hemichannel composition determines the FGF-1-induced membrane permeability and free [Ca2+]i responses. Mol. Biol. Cell 19, 35013513.

Schalper, K.A., Riquelme, M.A., Branes, M.C., Martinez, A.D., Vega, J.L., Berthoud, V.M., Bennett, M.V., Saez, J.C., 2012. Modulation of gap junction channels and hemichannels by growth factors. Mol. Biosyst. 8, 685-698.

Scolari, M.J., Acosta, G.B., 2007. D-Serine: a new word in the glutamatergic neuroglial language. Amino Acids 33, 563-574.

Seki, A., Coombs, W., Taffet, S.M., Delmar, M., 2004a. Loss of electrical communication, but not plaque formation, after mutations in the cytoplasmic loop of connexin43. Heart Rhythm 1, 227-233.

Seki, A., Duffy, H.S., Coombs, W., Spray, D.C., Taffet, S.M., Delmar, M., 2004b. Modifications in the biophysical properties of connexin43 channels by a peptide of the cytoplasmic loop region. Circ. Res. 95, e22-e28.

Severs, N.J., 1994. Gap junction alterations in the failing heart. Eur. Heart J. 15 (Suppl. D), 53-57.

Shibayama, J., Gutierrez, C., Gonzalez, D., Kieken, F., Seki, A., Carrion, J.R., Sorgen, P.L., Taffet, S.M., Barrio, L.C., Delmar, M., 2006. Effect of charge substitutions at residue his-142 on voltage gating of connexin43 channels. Biophys. J. 91, 40544063.

Shintani-Ishida, K., Uemura, K., Yoshida, K., 2007. Hemichannels in cardiomyocytes open transiently during ischemia and contribute to reperfusion injury following brief ischemia. Am. J. Physiol. Heart Circ. Physiol. 293, H1714-H1720.

Shiroshita-Takeshita, A., Sakabe, M., Haugan, K., Hennan, J.K., Nattel, S., 2007. Model-dependent effects of the gap junction conduction-enhancing antiarrhythmic peptide rotigaptide (ZP123) on experimental atrial fibrillation in dogs. Circulation 115, 310-318.

Siebert, A.P., Ma, Z., Grevet, J.D., Demuro, A., Parker, I., Foskett, J.K., 2013. Structural and functional similarities of calcium homeostasis modulator 1 (CALHM1) ion channel with connexins, pannexins, and innexins. J. Biol. Chem. 288, 61406153.

Simi, A., Tsakiri, N., Wang, P., Rothwell, N.J., 2007. Interleukin-1 and inflammatory neurodegeneration. Biochem. Soc. Trans. 35, 1122-1126.

Solan, J.L., Lampe, P.D., 2009. Connexin43 phosphorylation: structural changes and biological effects. Biochem. J. 419, 261-272.

Sorgen, P.L., Duffy, H.S., Sahoo, P., Coombs, W., Delmar, M., Spray, D.C., 2004a. Structural changes in the carboxyl terminus of the gap junction protein connexin43 indicates signaling between binding domains for c-Src and zonula occludens-1. J. Biol. Chem. 279, 54695-54701.

Sorgen, P.L., Duffy, H.S., Spray, D.C., Delmar, M., 2004b. pH-dependent dimerization of the carboxyl terminal domain of Cx43. Biophys. J. 87, 574-581.
Sosinsky, G.E., Boassa, D., Dermietzel, R., Duffy, H.S., Laird, D.W., MacVicar, B., Naus, C.C., Penuela, S., Scemes, E., Spray, D.C., Thompson, R.J., Zhao, H.B., Dahl, G., 2011. Pannexin channels are not gap junction hemichannels. Channels (Austin) 5, 193-197.

Spray, D.C., Harris, A.L., Bennett, M.V., 1981. Gap junctional conductance is a simple and sensitive function of intracellular $\mathrm{pH}$. Science 211, 712-715.

Srisakuldee, W., Jeyaraman, M.M., Nickel, B.E., Tanguy, S., Jiang, Z.S., Kardami, E., 2009. Phosphorylation of connexin-43 at serine 262 promotes a cardiac injuryresistant state. Cardiovasc. Res. 83, 672-681.

Stehberg, J., Moraga-Amaro, R., Salazar, C., Becerra, A., Echeverria, C., Orellana, J.A., Bultynck, G., Ponsaerts, R., Leybaert, L., Simon, F., Saez, J.C., Retamal, M.A., 2012. Release of gliotransmitters through astroglial connexin 43 hemichannels is necessary for fear memory consolidation in the basolateral amygdala. FASEB J. $26,3649-3657$.

Stergiopoulos, K., Alvarado, J.L., Mastroianni, M., Ek-Vitorin, J.F., Taffet, S.M., Delmar, M., 1999. Hetero-domain interactions as a mechanism for the regulation of connexin channels. Circ. Res. 84, 1144-1155.

Taruno, A., Vingtdeux, V., Ohmoto, M., Ma, Z., Dvoryanchikov, G., Li, A., Adrien, L., Zhao, H., Leung, S., Abernethy, M., Koppel, J., Davies, P., Civan, M.M., Chaudhari, N., Matsumoto, I., Hellekant, G., Tordoff, M.G., Marambaud, P., Foskett, J.K., 2013. CALHM1 ion channel mediates purinergic neurotransmission of sweet, bitter and umami tastes. Nature 495, 223-226.

Torres, A., Wang, F., Xu, Q., Fujita, T., Dobrowolski, R., Willecke, K., Takano, T., Nedergaard, M., 2012. Extracellular $\mathrm{Ca}(2)(+)$ acts as a mediator of communication from neurons to glia. Sci. Signal. 5, ra8.

Toyofuku, T., Akamatsu, Y., Zhang, H., Kuzuya, T., Tada, M., Hori, M., 2001. c-Src regulates the interaction between connexin-43 and $\mathrm{ZO}-1$ in cardiac myocytes. J. Biol. Chem. 276, 1780-1788.

Toyofuku, T., Yabuki, M., Otsu, K., Kuzuya, T., Hori, M., Tada, M., 1998. Direct association of the gap junction protein connexin-43 with ZO-1 in cardiac myocytes. J. Biol. Chem. 273, 12725-12731.

Vanden Abeele, F., Bidaux, G., Gordienko, D., Beck, B., Panchin, Y.V., Baranova, A.V., Ivanov, D.V., Skryma, R., Prevarskaya, N., 2006. Functional implications of calcium permeability of the channel formed by pannexin 1 . J. Cell Biol. 174, 535546.

Verkhratsky, A., Parpura, V., 2010. Recent advances in (patho)physiology of astroglia. Acta Pharmacol. Sin. 31, 1044-1054.

Verma, V., Larsen, B.D., Coombs, W., Lin, X., Sarrou, E., Taffet, S.M., Delmar, M., 2010. Design and characterization of the first peptidomimetic molecule that prevents acidification-induced closure of cardiac gap junctions. Heart Rhythm 7, 14911498.

Verma, V., Larsen, B.D., Coombs, W., Lin, X., Spagnol, G., Sorgen, P.L., Taffet, S.M., Delmar, M., 2009. Novel pharmacophores of connexin43 based on the "RXP" series of Cx43-binding peptides. Circ. Res. 105, 176-184.

Verselis, V.K., Bukauskas, F.F., 2002. Connexin-GFPs shed light on regulation of cellcell communication by gap junctions. Curr. Drug Targets 3, 483-499.

Volterra, A., Meldolesi, J., 2005. Astrocytes, from brain glue to communication elements: the revolution continues. Nat. Rev. Neurosci. 6, 626-640.

Wang, N., De Bock, M., Antoons, G., Gadicherla, A.K., Bol, M., Decrock, E., Evans, W.H., Sipido, K.R., Bukauskas, F.F., Leybaert, L., 2012. Connexin mimetic peptides inhibit Cx43 hemichannel opening triggered by voltage and intracellular Ca2+ elevation. Basic Res. Cardiol. 107, 304.

Wang, N., De Bock, M., Decrock, E., Bol, M., Gadicherla, A., Vinken, M., Rogiers, V., Bukauskas, F.F., Bultynck, G., Leybaert, L., 2013a. Paracrine signaling through plasma membrane hemichannels. Biochim. Biophys. Acta 1828, 35-50.

Wang, N., De Vuyst, E., Ponsaerts, R., Boengler, K., Palacios-Prado, N., Wauman, J., Lai, C.P., De Bock, M., Decrock, E., Bol, M., Vinken, M., Rogiers, V., Tavernier, J., Evans, W.H., Naus, C.C., Bukauskas, F.F., Sipido, K.R., Heusch, G., Schulz, R., Bultynck, G., Leybaert, L., 2013b. Selective inhibition of Cx43 hemichannels by Gap19 and its impact on myocardial ischemia/reperfusion injury. Basic Res. Cardiol. 108, 309.

Wang, R., Zhang, C., Ruan, Y., Liu, N., Wang, L., 2007. Changes in phosphorylation of connexin43 in rats during acute myocardial hypoxia and effects of antiarrhythmic peptide on the phosphorylation. J. Huazhong Univ. Sci. Technol. Med. Sci. 27, 241-244.

Weng, S., Lauven, M., Schaefer, T., Polontchouk, L., Grover, R., Dhein, S., 2002. Pharmacological modification of gap junction coupling by an antiarrhythmic peptide via protein kinase $C$ activation. FASEB J. 16, 1114-1116.

Wiegerinck, R.F., de Bakker, J.M., Opthof, T., de Jonge, N., Kirkels, H., WilmsSchopman, F.J., Coronel, R., 2009. The effect of enhanced gap junctional conductance on ventricular conduction in explanted hearts from patients with heart failure. Basic Res. Cardiol. 104, 321-332.

Wit, A.L., Duffy, H.S., 2008. Drug development for treatment of cardiac arrhythmias: targeting the gap junctions. Am. J. Physiol. Heart Circ. Physiol. 294, H16-H18. 